\title{
Overall performance evaluation of evolutionary designed conventional AGC controllers for interconnected electric power system studies in a deregulated market environment
}

\author{
Y.L. Karnavas*，K.S. Dedousis \\ Lab. of Electric Machines \& Installations, Dept. of Electrical Engineering \\ School of Applied Technology, Technological Educational Institution of Crete (TEIC), \\ PO Box 1939, Zip 710 04, Heraklion, Crete, Hellas, GREECE \\ "Corresponding Author: e-mail: karnab@staff.teicrete.gr
}

\begin{abstract}
Electric power industry is currently in transition from vertically integrated utilities to an industry that will incorporate competitive companies. This increases the complexity of the load frequency issue and calls for more insight and research. In this context, the tuning of a multi-area automatic generation control (AGC) system after deregulation and furthermore, the effect of reheat turbines dynamics in the power system performance, are not yet discussed in depth and are studied in this work. The effect of bilateral contracts on the dynamics of the system is taken into account and the concept of DISCO participation matrix for these bilateral contracts is simulated. Genetic algorithms are adopted in order to obtain the optimal parameters of the loadfrequency controllers as well as of the frequency biases of thermal systems with reheat turbines. Also, since the optimum parameter values of the classical AGC have been obtained in the literature by minimizing the popular integral of the squared errors criterion (ISE) only, an effort is made in this study to show that this criterion does not give always the best system performance especially in a deregulated environment. In this work, we investigate the optimum adjustment of the load frequency controllers using a set of performance indices which are various functions of error and time. In this way, someone can observe the various performances that such a kind of power system might have when a different performance index is used. It should be noted that to the extent of the authors' knowledge, this kind of optimization has not been done yet in the literature. The performances of the tuned two-area AGC system are obtained using appropriate Matlab/Simulink models. Finally, it is envisaged that the synthesis procedure highlighted in this paper could be of practical significance for tuning conventional AGC controllers for an interconnected thermal-electric power system in a deregulated environment.
\end{abstract}

Keywords: AGC, load frequency control, power systems, deregulation, bilateral contracts, genetic algorithms

\section{Introduction}

Many investigations have been reported in the past pertaining to AGC of a large interconnected power system (i.e Abdel-Magid and Dawoud, 1997, Aditya and Das, 2003, Cohn, 1986). A net interchange tie-line bias control strategy has also been widely accepted by utilities. The frequency and the interchanged power are kept at their desired values by means of feedback of the area control error (ACE) integral, containing the frequency deviation and the error of the tie-line power, and controlling the prime movers of the generators. The controllers so designed regulate the ACE to zero. For each area, a bias constant determines the relative importance attached to the frequency error feedback with respect to the tie-line power error feedback; the bias is very often equal to the natural area frequency response characteristic. Classical AGC corresponds basically to industry practice for the past years or so. The key assumptions are: (a) the steady-state frequency error following a step-load change should vanish and also the transient frequency and time errors should be small, (b) the static change in the tie power following a step-load in any area should be zero, provided each area can accommodate its own load change and (c) any area in need of power during emergency should be assisted from other areas. The key advantage of the classical AGC is that the control strategy is a totally decentralized one, in the sense that each control area carries out its own frequency and power regulation using locally gathered real-time information. 
On the other hand, the traditional power system industry has a vertically integrated utility structure. In the restructured or deregulated environment, vertically integrated utilities no longer exist. The utilities no longer own generation, transmission, and distribution; instead, there are three different entities, viz., GenCos (generation companies), TransCos (transmission companies) and DisCos (distribution companies). As there are several GenCos and DisCos in the deregulated structure, a DisCo has the freedom to have a contract with any GenCo for transaction of power. A DisCo may have a contract with a GenCo in another control area. Such transactions are called bilateral transactions. All the transactions have to be cleared through an impartial entity called an independent system operator (ISO). The ISO has to control a number of so-called ancillary services, one of which is AGC. For an in-depth discussion of implications of restructuring the power industry, the reader can refer to (Ilic et al, 1998, Sheble, 1999, Christie et al, 2000). So, it is obvious nowadays that in a restructured electric power system environment, the engineering aspects of planning and operation have to be reformulated. In most of the recent reported strategies, attempts have been made to adapt well-tested classical AGC schemes to the changing environment of power system operation under deregulation (Kumar et al, 1997, Delfino et al, 2002, Ibraheem et al, 2009, Sinha et al, 2010). Comprehensive studies on simulation and optimization in an AGC system after deregulation have been carried out by Donde et al as well as one of the authors (Donde, 2001, Karnavas, 2005). In Donde's work the concept of DisCo participation matrix (DPM) is proposed that helps the visualization and implementation of the contracts. The critical parameters in order to tune such a system are found to be the feedback integral gains of the conventional integral controllers as well as the frequency biases of the areas. In this work, all the three components of proportional plus integral plus derivative (PID) load frequency controllers are being examined, and a two-area AGC system block diagram in restructured environment is used to demonstrate the tuning procedure. Modifications are made in the area controllers which are extended to be I, PI and PID ones as well. A set of different performance indices which are various functions of error and time is also used here. In this way, someone can observe the various performances that such a kind of power system might have when a different performance index is used. It should be noted that to the extent of the authors' knowledge, this kind of optimization has not been done yet in the literature. The paper is organized as follows. In the next section the block diagram of the two-area four-GenCos AGC system is modeled, described and its aspects are discussed. The reheat type steam turbine model is also implemented there. GAs details and the tuning procedure are given next. The GA tuning is applied to three case studies described in the fourth Section concerning normal and contract violation situations, and the simulation results which are summarized in fifth section show the effectiveness of the proposed tuning procedure. Finally, in the conclusion Section, some comments are given as well as some thoughts for future work.

\section{The Deregulated Market Environment for AGC}

The traditional AGC is well discussed in numerous works (i.e. Elgerd, 1970, Karnavas and Papadopoulos, 2002, Pan and Lian, 2005) while research work in deregulated AGC can be found in (Kumar et al, 1997, Delfino et al, 2002, Donde et al, 2001, Christie and Bose, 1996, Nobile et al, 2000, Bevrani et al, 2004, Karnavas, 2005, Shayeghi et al, 2006, Demiroren and Zeynelgil, 2007, Srinivasa et al, 2008). In the new restructured environment (see Figure 1), GenCos sell power to various DisCos at competitive prices. DisCos have the liberty to choose the GenCos for their contracts. They may or may not have contracts with the GenCos in their own area. This makes various combinations of GenCo-DisCo contracts possible in practice (Figure 2). The block diagram in Figure 3 shows how the bilateral contracts are incorporated in the traditional AGC system. The system is modeled in Matlab/Simulink and the area controllers are replaced with I or PI or PID ones. Each area includes two identical GenCos and two DisCos. With respect to Figure 3, the four loads of the DisCos are stored in the DISCO block. It should be noted also that the two power systems have equal nominal installed capacities. Furthermore, the developed model for a GenCo is shown in Figure 4, and the reheater transfer function block is taken from Kumar et al (1985). Finally, the used model for the conventional controllers is shown in Figure 5. The controller's demand signal is distributed according to the area participation factors (apf) block. Each GenCo is represented by a governor, a reheater and a turbine. All the system data are given for clarity in the Appendix A.

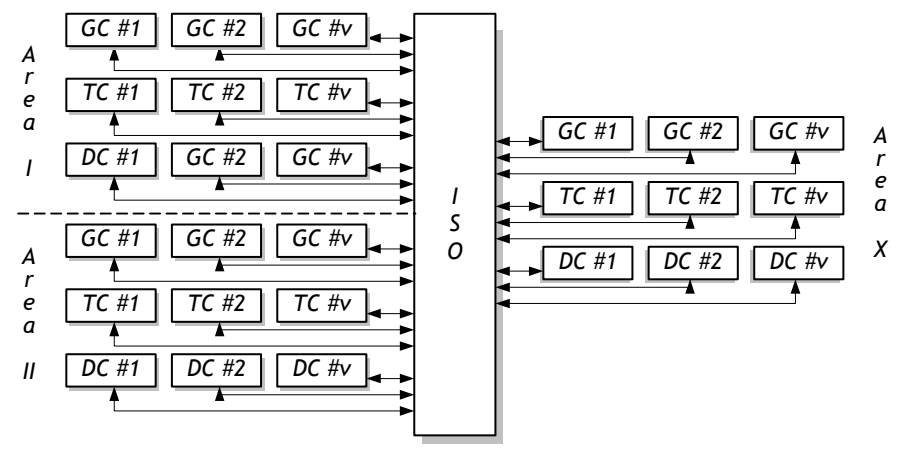

Figure 1. Interconnection between generation (GC), transmission (TC) and distribution (DC) companies in a deregulated environment operated by independent system operator (ISO). 


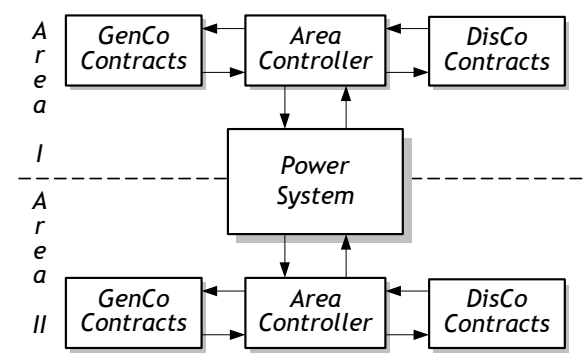

Figure 2. Schematic of a two-area AGC model in a restructured environment.

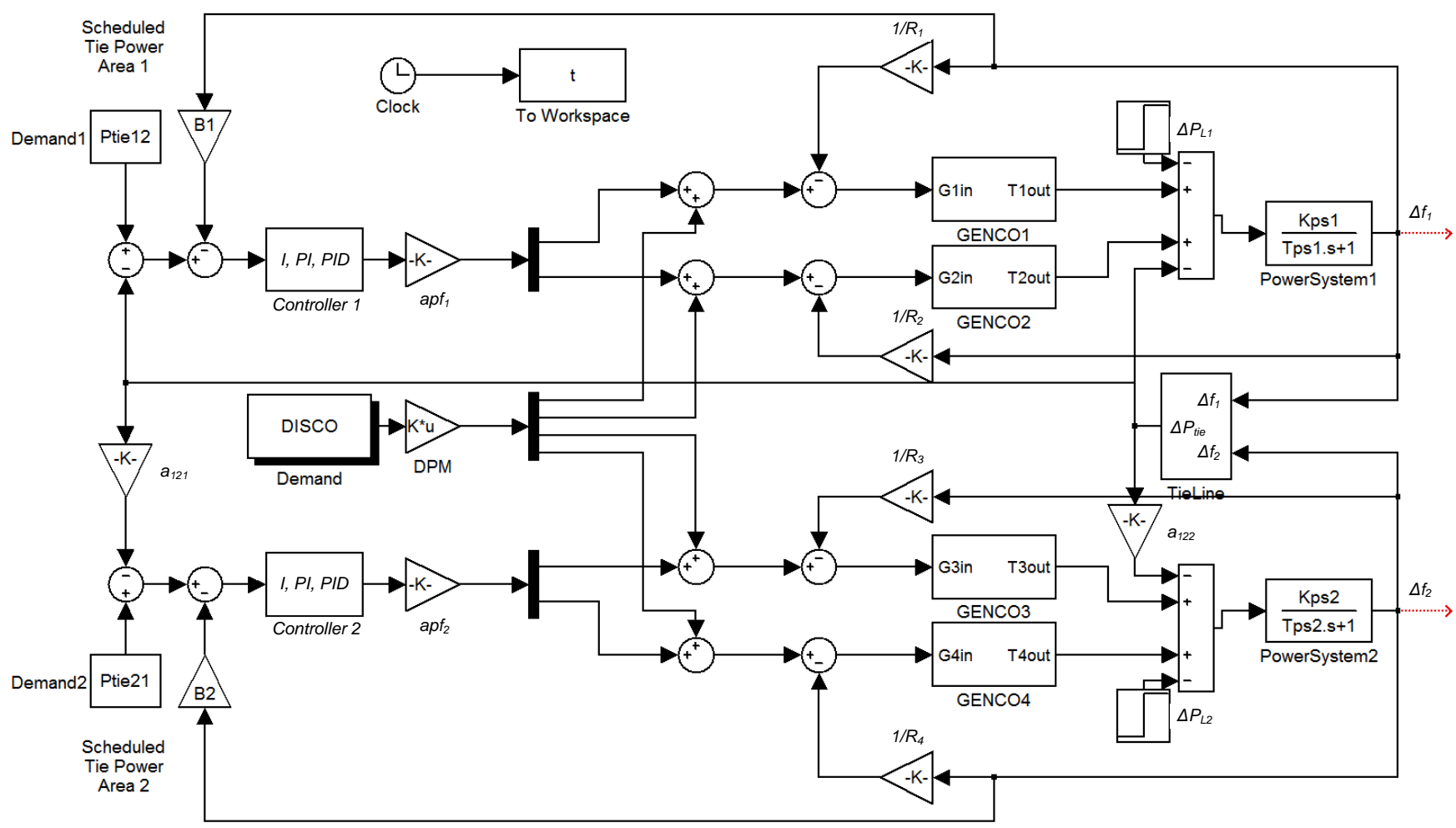

Figure 3. Developed model of a two-area double-GenCo AGC system with controllers.

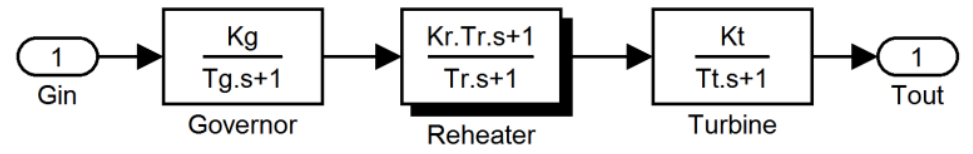

Figure 4. Developed model of a GenCo with a reheat turbine.

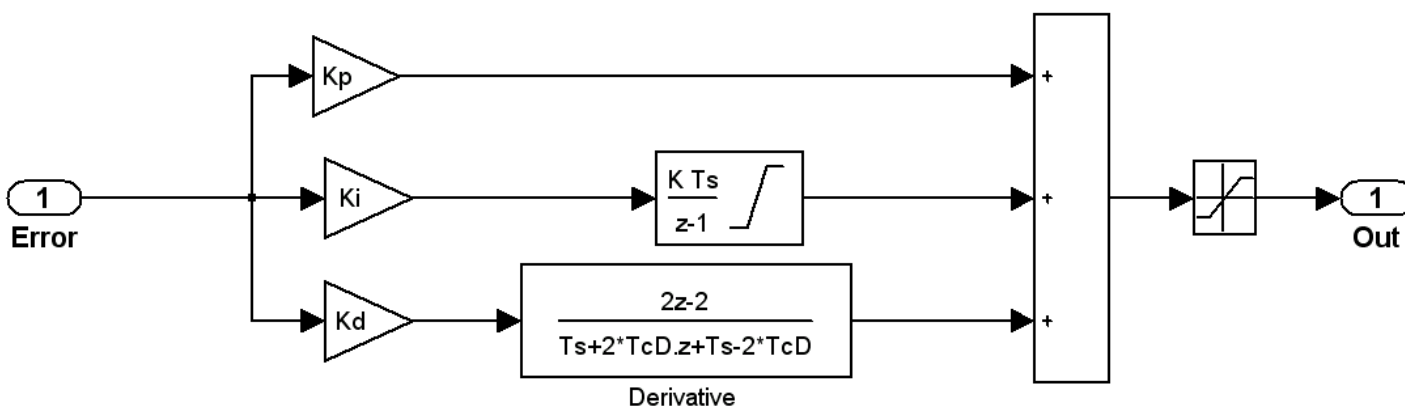

Figure 5. Discrete PID-type controller used in this study. 
Depending on the contracts made between GenCos and DisCos, the DPM is set. DPM is a matrix with the number of rows equal to the number of GenCos and the number of columns equal to the number of DisCos in the system (see Eq. 1). Each entry in this matrix can be thought of as a fraction of a total load contracted by $j^{\text {th }}$ DisCo towards the $i^{\text {th }}$ GenCo and is called contract participation factor (cpf) as seen in Eq. 2.

where

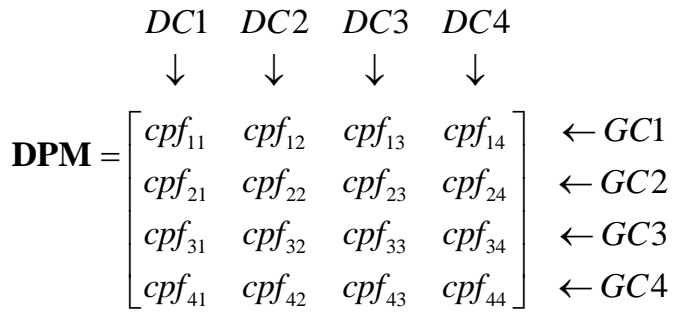

$$
c p f_{i j}=\frac{j^{\text {th }} \text { DisCo's power demand out of } i^{\text {th }} \text { GenCo [pu.MW] }}{j^{\text {th }} \text { DisCo's total power demand [pu.MW] }}
$$

Whenever a load demanded by a DisCo changes, it is reflected as a local load in the area to which this DisCo belongs. This corresponds to the local loads $\Delta P_{L I}$ and $\Delta P_{L 2}$ and should be reflected in the deregulated AGC system block diagram at the point of input to the power system block. As there are many GenCos in each area, ACE signal has to be distributed among them in proportion to their participation in the AGC. Coefficients that distribute ACE to several GenCos are termed (as described above) ACE participation factors (apf). Note that $\sum_{j=1}^{m}\left(a p f_{j}\right)=1$ where $m$ is the number of GenCos. Thus, as a particular set of GenCos are supposed to follow the load demanded by a DisCo, information signals must flow from a DisCo to a particular GenCo specifying corresponding demands. These signals (which were absent from the traditional AGC scenario) describing the partial demands, are specified by the cpfs and the puMW load of a DisCo. These signals carry information as to which GenCo has to follow a load demanded by which DisCo. In our case of two areas (I, II), the scheduled steady state power flow on the tie-line is given as

$$
\begin{aligned}
\Delta P_{\text {tie } \text { I-II }}^{\text {shedled }}= & (\text { Demand of DisCos in area II from GenCos in area I })- \\
& -(\text { Demand of DisCos in area I from GenCos in area II })
\end{aligned}
$$

At any given time, the tie line power error is defined:

$$
\Delta P_{\text {tie }}^{i}=\Delta P_{\text {tie }}^{\text {actual }, i}-\Delta P_{\text {tie }}^{\text {scheduled, } i}
$$

This error vanishes in the steady state as the actual tie line power flow reaches the scheduled power flow. This error signal is used to generate the respective ACE signals as in the traditional scenario. Thus, the area control error (ACE) for the $i^{\text {th }}$ area at any time instant $t$ is defined as,

$$
A C E^{i}(t)=e^{i}(t)=\Delta P_{t i e}^{i}(t)+B_{i} \Delta f_{i}(t)
$$

where $\Delta P_{t i e 2-1}=\left(-P_{r 1} / P_{r 2}\right) \Delta P_{t i e 1-2}$ and $P_{r 1}, P_{r 2}$ are the rated installed capacities of areas I and II, respectively. Consequently, $A C E_{1}=B_{1} \Delta f_{1}+a_{12} \Delta P_{\text {tiel-2 }}$ and $A C E_{2}=B_{2} \Delta f_{2}+a_{12} \Delta P_{\text {tiel-2 }}$ where $a_{12}=-\mathrm{P}_{\mathrm{r} 1} / \mathrm{P}_{\mathrm{r} 2}$. Therefore, in this work the required GenCos production is given by:

\section{GENCO $=$ DPM $\times$ DISCO}

Finally, for this work, the controllers' gains as well as the frequency biases are set to be equal for both areas.

\subsection{Control Strategies under Study}

The conventional automatic generation controller found mostly in literature has a linear integral only control strategy of the following form and also sometimes researchers use continuous time models which are completely inappropriate, i.e.

$$
u_{i}=-K_{I}^{i} \int e^{i}(t) d t
$$


In this work, for achieving the basic objectives of load-frequency control problem, i.e., zero steady-state error in frequency and tieline power, and also for completeness purposes since our goal is the overall conventional controllers' performance evaluation, the discrete type of integral (I), proportional plus integral (PI) and proportional plus integral plus derivative (PID) controller is used (taken from Simulink/Matlab library) as already shown in Figure. 5. Parameter tuning and in depth discussion of such type of controllers can be found in Wu and Huang (1997). In our case, the control law for the $i^{\text {th }}$ area $(i=1,2)$ is given by

$$
u_{i}=-K_{P}^{i} e^{i}(t)-K_{I}^{i} \int e^{i}(t) d t-K_{D}^{i}\left(\frac{d e^{i}(t)}{d t}\right)
$$

which when implemented in the Simulink/Matlab environment takes the form

$$
u_{i}=-K_{P}^{i} e^{i}(k T s)-K_{I}^{i} \sum_{0}^{T s i m} e^{i}(k T s) \Delta t-K_{D}^{i}\left(\frac{\Delta e^{i}(k T s)}{\Delta t}\right)
$$

where $K_{I}^{i}, K_{P}{ }^{i}$ and $K_{D}{ }^{i}$ are the gains of the PID controllers $\left(K_{P}{ }^{i}, K_{D}{ }^{i}\right.$ or $K_{D}{ }^{i}$ are set to zero when a I or a PI is needed respectively), $T_{s}$ is the sampling time, $T_{\text {sim }}$ is the total simulation time and $k=1,2, . ., T_{\text {sim }} / T_{s}$. In this study, the optimum values of these gains along with the bias factor $B^{i}$ which minimize a whole set of different performance indices are easily and accurately computed using a genetic algorithm. In a typical run of the GA, an initial population is referred to as the $0^{\text {th }}$ generation. Each individual in the initial population has an associated performance index value. Using the performance index information, the GA then produces a new population. The application of a GA involves repetitively performing two steps: (a) the calculation of the performance index for each of the individuals in the current population. To do this, the system must be simulated to obtain the value of the performance index; (b) the GA then produces the next generation of individuals using the reproduction, crossover and mutation operators. These two steps are repeated from generation to generation until the population has converged, producing the optimum parameters. A flowchart of the GA optimization procedure is given in Figure 6.

\section{Genetic Algorithm Overview and Implementation Aspects}

Genetic algorithms (GA), a way to search randomly for the best answers to tough problems were first introduced by Holland (1975). Over the past years, it is becoming important to solve a wide range of search, optimization and machine learning problems. A GA is an iterative procedure which maintains a constant size population of candidate solutions. The algorithm begins with a randomly selected population of function inputs represented by string of bits. During each iteration step, called a generation, the structures in the current population are evaluated and on the basis of this evaluation, a new population of candidate solution is formed. That is GA uses the current population of string to create a new population such that the strings in the new population are on average better than those in the current population. The idea is to use the best elements from the current population to help form the new population. If this is done correctly, then the new population will on average be better than the old population. Three basic processes, namely selection, mating (or crossover) and mutation are used to make the transition from one population generation to the next. In addition, GA works with a coding of parameters rather than the parameters themselves, thereby freeing itself of the limitations (e.g. continuity and derivative existence) of conventional techniques such as gradient methods (Wu and Huang, 1997). The simplified genetic algorithm cycle based on the above is shown in Figure 6, while the main pseudo-code implemented in MATLAB environment for this work is depicted in Figure 7.

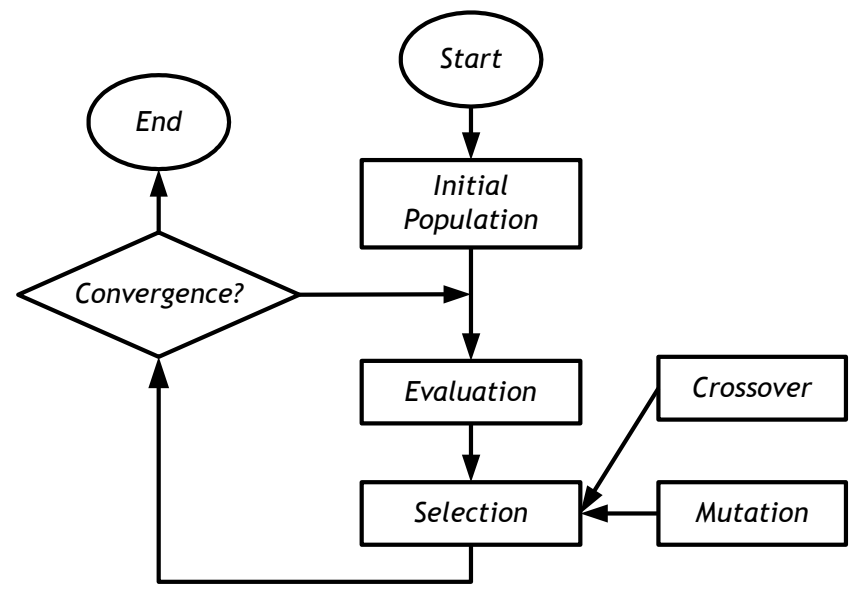

Figure 6. Simplified flowchart of a typical GA. 


\subsection{GA's Processes}

The above three steps are repeated to create each new generation. And it continues in this fashion until some stopping condition is reached (e.g. maximum number of generations or resulting new population not improving fast enough).

Selection: This is the first step of the three genetic operations. It determines which strings in the current population will be used to create the next generation. This is done by using a biased random selection methodology. That is, parents are randomly selected from the current population in such a way that the "best" strings in the population have the greatest chance of being selected. There are many ways to do this. One wide known technique is roulette wheel parent selection (Grefenstette, 1986) which is also used here.

Crossover: This is a randomized yet structured recombination operation. Simple crossover may proceed in two steps. First, the newly reproduced strings in the mating pool are mated at random. Second, crossover of each pair of strings is done as follows: (i) an integer position $p$ along a string is selected at random in the intervals [1, $L-1]$, where $L$ is the string length and (ii) two new strings are created by swapping all characters between position 1 and $p$ inclusively.

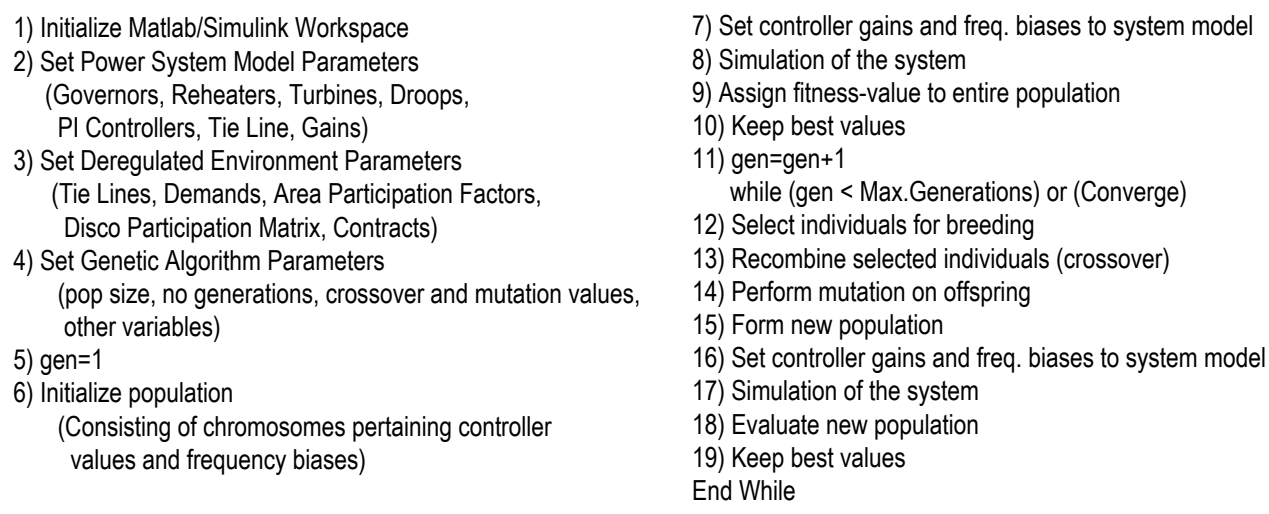

1) Initialize Matlab/Simulink Workspace

2) Set Power System Model Parameters (Governors, Reheaters, Turbines, Droops, PI Controllers, Tie Line, Gains)

3) Set Deregulated Environment Parameters (Tie Lines, Demands, Area Participation Factors, Disco Participation Matrix, Contracts)

4) Set Genetic Algorithm Parameters (pop size, no generations, crossover and mutation values, other variables)

5) gen $=1$

6) Initialize population

(Consisting of chromosomes pertaining controller values and frequency biases)

Figure 7. Genetic algorithm pseudo-code as applied to this work.

Mutation: Reproduction and crossover effectively search and recombine the existing chromosomes. However, they do not create any new genetic material in the population. Mutation is capable of overcoming this shortcoming. It is an occasional random alteration of a string position. In the binary string representation, this simply means changing a 1 to 0 or vice versa. This random mutation provides background variation and occasionally introduces beneficial materials into the population.

\subsection{GA's Parameters Selection}

Genetic parameters, namely population size, crossover rate $\left(P_{c}\right)$ and mutation rate $\left(P_{m}\right)$, are the entities that help to tune the performance of the GAs. The selection of values for these parameters plays an important role in obtaining an optimal solution. There are no deterministic rules to decide these values, but there are some general guidelines which can be followed to arrive at optimal values for these parameters and which can be found in Holland (1975).

Control Parameters Selected: First of all, the effect of population sizes for different test cases was observed. Different populations $(20,50,60,80$, and 100) were considered and it has been observed that the population size 50 or even 40 was satisfactory. After selecting the population size, the effect of mutation and crossover probabilities was examined. It has been found that suitable combination of mutation and crossover probabilities giving the best performances varies with test cases. Different combinations of mutation probabilities $(0.0001,0.001,0.005,0.01)$ and crossover probabilities $(0.6,0.8,0.9$, and 1.0$)$ were tested and it was found that $P_{c}=1.0$ and $P_{m}=0.005$ give the best performance for all the test cases.

Encoding: The design variables are mapped onto a fixed-length binary digit string which is constructed over the binary alphabet $\{0,1\}$, and is concatenated head-to-tail to form one long string called a chromosome. That is, every string contains all design variables. Each design variable is represented by a $\lambda$-bit string. We have to determine the value of $\lambda$. It is shown by Lin and Hajela (1992) that:

$$
\lambda \geq \log _{2} \frac{x^{u}-x^{l}}{\varepsilon}
$$

where $x^{u}=$ upper bound on $x ; x^{l}=$ lower bounds on $x ; \varepsilon=$ the resolution. For example, if $\varepsilon=0.01, x^{u}=60.0, x^{l}=20.0$, then $\lambda \geq 12$. Decoding: The physical value of design variable $x$ is computed from the following equation

$$
x=x^{l}+I \frac{x^{u}-x^{l}}{2^{\lambda}-1}
$$


For example, if $\varepsilon=0.01, x^{u}=60.0, x^{l}=20.0$ and $\lambda=12$, then the bit string 100000000001 is decoded to $\mathrm{I}=2049$ and thus $x=40.014652$. During the optimization process upper and lower bounds of all the controllers' gain settings and bias factors were selected as [-50, 50] respectively, and the bit size (gene length) of each variable as 20 (i.e. $\lambda=20$ ).

\subsection{Fitness-Objective Function and Performance Indices under Consideration}

In GAs, the value of fitness represents the performance which is used to rank the string 0 , and the ranking is then used to determine how to allocate reproductive opportunities. This means that individuals with a higher fitness value will have a higher opportunity of being selected as a parent. Thus, fitness is some measure of goodness to be maximized. The fitness function is essentially the objective function for the problem. In unconstrained maximization problem, the objective function can be directly adopted as the fitness function $F=J$ where $F$ is the fitness function and $J$ is the objective function. The unconstrained minimization problem according to the equation $F=K / J$ where $K$ is a positive constant multiplier. To maximize the fitness function is the same as minimizing the objective function.

The transient performance of the two area interconnected power system in the deregulated environment with respect to the control of the frequency and tie line powers obviously depends on the value of the controllers' gains and the frequency bias. The optimum parameter values of the classical AGC have been obtained in the literature (using integral or proportional-plus-integral) by minimizing the popular integral of the squared error criterion (ISE) (Abdel-Magid and Dawoud, 1997). This criterion has been used because of the ease of computing the integral both analytically and experimentally. A characteristic of the ISE criterion is that it weights large errors heavily and small errors lightly and it is not very selective. A system designed by this criterion tends to show a rapid decrease in a large initial error. Hence the response is fast, oscillatory and the system has poor relative stability.

In this work, we investigate the optimum adjustment of the load frequency controllers by extending this issue, by incorporating a set of performance indices which are various functions of error and time. In this way, someone can observe the various performances that such a kind of power system might have when a different performance index is used. It should be noted that to the extent of the authors' knowledge, this kind of optimization has not been done in the literature before. Finally, it is envisaged that the synthesis procedure highlighted in this paper could be of practical significance for tuning those AGC parameters for similar power systems. The indices adopted here include:

(a) The integral of the square of the error criterion (ISE) which is given by:

$$
I S E=\int_{0}^{\infty} e^{2}(t) d t
$$

(b) The integral of time-multiplied absolute value of the error criterion (ITAE) which is given by:

$$
\text { ITAE }=\int_{0}^{\infty} t|e(t)| d t
$$

This criterion penalizes long duration transients and is much more selective than the ISE. A system designed by use of this criterion exhibits small overshoot and well damped oscillations.

(c) The integral of time-multiplied square of the error criterion (ITSE) which is given by:

$$
\text { ITSE }=\int_{0}^{\infty} t e^{2}(t) d t
$$

This criterion weights large initial error lightly, while errors occurring late in the transient response are penalized heavily. This criterion has a better selectivity than the ISE.

(d) The integral of squared time-multiplied absolute value of the error criterion (ISTAE) which is given by:

$$
\text { ISTAE }=\int_{0}^{\infty} t^{2}|e(t)| d t
$$

(e) The integral of squared time-multiplied square of the error criterion (ISTSE) which is given by:

$$
\text { ISTSE }=\int_{0}^{\infty} t^{2} e^{2}(t) d t
$$

Even though performance indices (c) through (e) have not been applied to any great extend in practice due to the increased difficulty in handling them, they are considered here. If the power system model of Figure 1 is taken into account and also, a discrete time control is performed, Eqs. (12)-(16), are then translated into the following forms respectively

$$
\begin{gathered}
J_{1}=I S E=\sum_{0}^{T s i m}\left(\Delta P_{\text {tie }}^{2}+\alpha \Delta f_{1}^{2}+\beta \Delta f_{2}^{2}\right) \Delta t \\
J_{2}=I T A E=\sum_{0}^{T s i m} t\left(\left|\Delta P_{\text {tie }}\right|+\alpha\left|\Delta f_{1}\right|+\beta\left|\Delta f_{2}\right|\right) \Delta t
\end{gathered}
$$




$$
\begin{gathered}
J_{3}=I T S E=\sum_{0}^{T s i m} t\left(\Delta P_{\text {tie }}^{2}+\alpha \Delta f_{1}^{2}+\beta \Delta f_{2}^{2}\right) \Delta t \\
J_{4}=I S T A E=\sum_{0}^{T s i m} t^{2}\left(\left|\Delta P_{\text {tie }}\right|+\alpha\left|\Delta f_{1}\right|+\beta\left|\Delta f_{2}\right|\right) \Delta t \\
J_{5}=I S T S E=\sum_{0}^{T s i m} t^{2}\left(\Delta P_{\text {tie }}^{2}+\alpha \Delta f_{1}^{2}+\beta \Delta f_{2}^{2}\right) \Delta t
\end{gathered}
$$

where $J_{m}(m=1 . .5)$ is the objective function as described above and $\alpha, \beta$ are penalty coefficients which in our case are set to unity. To compute the optimum parameter values, unit step load changes are assumed in one or both areas and the performance index is minimized using the GA. In the next Section, the optimum values of the parameters $K_{P}{ }^{i}, K_{I}{ }^{i}, K_{D}{ }^{i}$ and $B^{i}$ resulting from minimizing the five different performance indices are presented.

Since each performance index gives values in different orders of magnitude, a common performance measure must be also adopted for comparison purposes between them. Thus, the integral or absolute error (IAE) is introduced here which gives the area under each curve through time and can be expressed as

$$
J_{c}=I A E=\sum_{0}^{T s i m}\left(\left|\Delta P_{\text {tie }}\right|+\alpha\left|\Delta f_{1}\right|+\beta\left|\Delta f_{2}\right|\right) \Delta t
$$

\section{Case Studies}

The proposed controllers are applied for each control area of the restructured power system as shown in Figure 3. To illustrate robustness of the proposed control strategies against parametric uncertainties and contract variations, simulations are carried out for three cases of possible contracts under various operating conditions and load demands (Karnavas, 2005).

\subsection{Case 1: Exclusive Case:}

The GenCos in each area participate equally in AGC; i.e., all four apf values are equal to 0.5. Contracts are made only between DisCos in area I and GenCos in area I, to purchase 0.1 puMW for each of them. In other words the load change occurs only in area 1. The following data are applicable for this case:

$$
\mathbf{D P M}=\left[\begin{array}{cccc}
0.5 & 0.5 & 0 & 0 \\
0.5 & 0.5 & 0 & 0 \\
0 & 0 & 0 & 0 \\
0 & 0 & 0 & 0
\end{array}\right], \mathbf{D I S C O}=\left[\begin{array}{c}
0.1 \\
0.1 \\
0 \\
0
\end{array}\right] p u M W
$$

Each area's load is the sum of the local DisCos demand, i.e. $\triangle P L_{l}=0.2$ and therefore $\triangle P L_{2}=0$.

\subsection{Case 2: Normal Case:}

All the DisCos contract with the GenCos for power as per the following DPM:

$$
\mathbf{D P M}=\left[\begin{array}{cccc}
0.5 & 0.25 & 0 & 0.3 \\
0.2 & 0.25 & 0 & 0 \\
0 & 0.25 & 1 & 0.7 \\
0.3 & 0.25 & 0 & 0
\end{array}\right], \mathbf{D I S C O}=\left[\begin{array}{c}
0.105 \\
0.045 \\
0.195 \\
0.055
\end{array}\right] p u M W
$$

It is assumed that each DisCo demands 0.1 puMW power from GenCos as defined by cpfs in DPM matrix and each GenCo participates in $\mathrm{AGC}$ by following $a p f \mathrm{~s}: \operatorname{apf}_{1}=0.75, \operatorname{apf}_{2}=0.25, \operatorname{apf}_{3}=0.5, a p f_{4}=0.5$. Also, $\triangle P L_{1}=0.15$ and therefore $\triangle P L_{2}=0.25$.

\subsection{Case 3: Contract Violation Case:}

It may happen that a DisCo violates a contract by demanding more power than that specified in the contract. This excess power is not contracted out to any GenCo. This un-contracted power must be supplied by the GenCos in the same area as the DisCo. It must be reflected as a local load of the area but not as the contract demand. So, consider Case 2 again with a modification that DisCo1 demands 0.1 puMW of excess power, which is reflected now in $\triangle P L_{l}$ which now is set to $\triangle P L_{l}=0.25$. 


\section{Simulation Results and Discussion}

The time responses of the system are simulated and the signals are sampled at $100 \mathrm{~Hz}$. These responses are presented in Figures 8-10 for the I-type controller, in Figures 11-13 for the PI-type controller and in Figures 14-16 for the three cases respectively. All these results show the effects of the load change in: (a) the areas' frequency deviations, (b) the generated powers of the various GenCos following the step change in the load demands of the DisCos and (c) the actual power flow on the tie line (e.g. in a direction from area I to area II for Case 1). Visually, the GA-tuned system has quite fast frequency response. The frequency deviation in each area goes to zero in the steady state. Also, in the steady state, generation of a GenCo matches the demand of the DisCos in contract with it. Generally speaking, it can be said that no matter the type of controller adopted, each one seem to succeed to come to steady state quite easily and also satisfactorily (but of course they pertain small oscillations around the nominal value i.e. $\Delta f=0$ ). By inspection of the aforementioned figures it is also clear that, when PID-type controllers are used, they act too fast to the generator inputs (this is not desirable due to the wear and tear of the machines) and also exhibit very fast oscillations. Thus, I-type or PI-type controllers seem to be the better choice for the system under study especially when they are to be tuned properly. Apart from that, in all cases, an acceptable overshoot and settling time on frequency deviation signal in each control area is maintained and also, a reasonable limit on the control action signal, in the viewpoint of change speed and amplitude, is assured.

Tables 1-3 give the optimum controller gain $\left(K_{I}^{i}\right)$ for the I-type controller, Tables 4-6 give the optimum controller gains $\left(K_{P}^{i}, K_{I}^{i}\right)$ for the PI-type controller and Tables 7-9 give the optimum controller gains $\left(K_{P}{ }^{i}, K_{I}^{i}, K_{D}{ }^{i}\right)$ for the PID-type controller. Also in these Tables, the values of the frequency biases $B^{i}$ for the two areas obtained by the application of the GA are given along with the corresponding objective function value $\left(J_{m}\right)$ and the values of the common (comparative) performance measure $\left(J_{c}\right)$. It is clearly shown that for different cases, different performance indices give the best optimization parameters values. The latter proves that when research work is done in such kind of power system models, several performance indices must be examined thoroughly before extracting valuable information about the correct system controller's tuning.

Another interesting thing to observe from Figures 8-16 (in most cases and excluding the PID-type control) is that the quantities that are involved to the objective function (i.e. $\Delta f$ and $\Delta P_{\text {tie }}$ ), have the fastest response when the PI-type controllers are applied, but the rest quantities (i.e. the generated powers of the GenCos) have the fastest response and with less oscillations when the I-type controllers are applied. This also leads to the conclusion that the choice of the objective function is crucial and the behavior of the tuned system is directly depended on it.

Table 1. Optimum values for I-type controller gains, frequency biases and fitness function obtained by GA for Case 1.

\begin{tabular}{rrrrrr} 
& \multicolumn{1}{c}{ ISE } & \multicolumn{1}{c}{ ITAE } & \multicolumn{1}{c}{ ITSE } & \multicolumn{1}{c}{ ISTAE } & \multicolumn{1}{c}{ ISTSE } \\
\hline$K_{I}^{i}$ & 0.0692 & 1.4867 & 0.7110 & 1.2059 & 0.0569 \\
$B^{i}$ & 3.5383 & 0.2180 & 0.3395 & 0.3056 & 0.2342 \\
$J_{m}$ & 133.8353 & 548497.4906 & 21953.0808 & 420239883.6861 & 8891752.1239 \\
$J_{c}$ & 1401.0005 & 1396.5185 & $\mathbf{1 3 7 1 . 8 6 5 3}$ & 1395.9370 & 1429.2178 \\
\hline
\end{tabular}

Table 2. Optimum values for I-type controller gains, frequency biases and fitness function obtained by GA for Case 2.

\begin{tabular}{rrrrrr} 
& \multicolumn{1}{c}{$I S E$} & \multicolumn{1}{c}{$I T A E$} & \multicolumn{1}{c}{ ITSE } & \multicolumn{1}{c}{ ISTAE } & \multicolumn{1}{c}{ ISTSE } \\
\hline$K_{I}^{i}$ & 0.2871 & 0.8317 & 0.6628 & 0.9254 & 0.4085 \\
$B^{i}$ & 1.4112 & 0.6322 & 0.6617 & 0.5669 & 1.2710 \\
$J_{m}$ & 285.1501 & 550555.8858 & 33268.4512 & 431862160.6771 & 10803805.4679 \\
$J_{c}$ & 1728.1945 & $\mathbf{1 6 3 6 . 2 7 6 4}$ & 1650.6018 & 1637.7884 & 1665.6872 \\
\hline
\end{tabular}

Table 3. Optimum values for I-type controller gains, frequency biases and fitness function obtained by GA for Case 3.

\begin{tabular}{rrrrrr} 
& \multicolumn{1}{c}{$I S E$} & \multicolumn{1}{c}{$I T A E$} & \multicolumn{1}{c}{ ITSE } & \multicolumn{1}{c}{ ISTAE } & \multicolumn{1}{c}{ ISTSE } \\
\hline$K_{I}^{i}$ & 0.9218 & 0.9996 & 0.8219 & 0.7247 & 0.7439 \\
$B^{i}$ & 0.5215 & 0.6116 & 0.5884 & 0.8643 & 0.7589 \\
$J_{m}$ & 496.0482 & 594636.4936 & 50498.0860 & 438934198.7124 & 12625614.6107 \\
$J_{c}$ & 2026.8078 & $\mathbf{2 0 0 7 . 5 4 4 9}$ & 2034.7790 & 2030.2019 & 2025.1652 \\
\hline
\end{tabular}

Table 4. Optimum values for PI-type controller gains, frequency biases and fitness function obtained by GA for Case 1.

\begin{tabular}{rrrrrr} 
& \multicolumn{1}{c}{$I S E$} & \multicolumn{1}{c}{ ITAE } & \multicolumn{1}{c}{ ITSE } & \multicolumn{1}{c}{ ISTAE } & \multicolumn{1}{c}{ ISTSE } \\
\hline$K_{P}{ }^{i}$ & -0.1964 & 0.3311 & -0.1179 & -0.6538 & -0.7664 \\
$K_{I}{ }^{i}$ & -0.0055 & 0.0105 & -0.0038 & 1.4550 & 1.8849 \\
$B^{i}$ & -6.7169 & 1.6175 & -7.7037 & 0.3761 & 0.2210 \\
$J_{m}$ & 75.8010 & 513978.2119 & 17054.2253 & 242263510.1152 & 4594143.2581 \\
$J_{c}$ & 1243.5717 & 1205.5894 & $\mathbf{1 1 8 8 . 7 4 5 4}$ & 1401.9248 & 1227.6306 \\
\hline
\end{tabular}


Table 5. Optimum values for PI-type controller gains, frequency biases and fitness function obtained by GA for Case 2.

\begin{tabular}{rrrrrr}
\hline & \multicolumn{1}{c}{ ISE } & \multicolumn{1}{c}{ ITAE } & \multicolumn{1}{c}{ ITSE } & \multicolumn{1}{c}{ ISTAE } & \multicolumn{1}{c}{ ISTSE } \\
\hline$K_{P}{ }^{i}$ & -1.2968 & -0.4640 & 0.3264 & -0.7073 & -0.2618 \\
$K_{I}{ }^{i}$ & -0.3681 & 2.2838 & 0.2304 & -0.7557 & -0.7422 \\
$B^{i}$ & -0.9744 & 0.2516 & 2.1264 & -1.6999 & -1.3028 \\
$J_{m}$ & 115.8009 & 519320.0472 & 20667.1899 & 343451399.8030 & 7347239.0185 \\
$J_{c}$ & $\mathbf{1 1 6 8 . 4 1 6 2}$ & 1783.2774 & 1341.6084 & 1328.8407 & 1404.0484 \\
\hline
\end{tabular}

Table 6. Optimum values for PI-type controller gains, frequency biases and fitness function obtained by GA for Case 3.

\begin{tabular}{rrrrrr}
\hline & \multicolumn{1}{c}{$I S E$} & \multicolumn{1}{c}{ ITAE } & \multicolumn{1}{c}{ ITSE } & \multicolumn{1}{c}{ ISTAE } & \multicolumn{1}{c}{ ISTSE } \\
\hline$K_{P}{ }^{i}$ & 0.5846 & 0.1329 & 0.4658 & -0.1014 & -0.1699 \\
$K_{I}{ }^{i}$ & 0.1769 & 0.5836 & 0.3323 & 0.8977 & 2.1173 \\
$B^{i}$ & 2.5360 & 1.1443 & 1.8436 & 0.7016 & 0.2515 \\
$J_{m}$ & 199.2844 & 588128.6877 & 25992.1344 & 426312133.5791 & 13535587.3574 \\
$J_{c}$ & 1766.0177 & 1853.4039 & $\mathbf{1 5 8 7 . 7 6 3 4}$ & 2166.3469 & 2067.8091 \\
\hline
\end{tabular}

Table 7. Optimum values for PID-type controller gains, frequency biases and fitness function obtained by GA for Case 1.

\begin{tabular}{rrrrrr}
\hline & \multicolumn{1}{c}{$I S E$} & \multicolumn{1}{c}{$I T A E$} & \multicolumn{1}{c}{ ITSE } & \multicolumn{1}{c}{ ISTAE } & \multicolumn{1}{c}{ ISTSE } \\
\hline$K_{P}{ }^{i}$ & 2.4297 & 3.4432 & 7.0889 & 6.8616 & 9.0484 \\
$K_{I}{ }^{i}$ & 11.8674 & 47.6944 & 26.8778 & 94.9188 & 47.9638 \\
$K_{D}{ }^{i}$ & 1.1285 & 0.7832 & 2.2484 & 1.4102 & 2.3543 \\
$B^{i}$ & 4.4101 & 5.2857 & 1.7220 & 2.6488 & 1.4293 \\
$J_{m}$ & 0.6660 & 2996.6590 & 19.1299 & 1027809.5262 & 1101.6672 \\
$J_{c}$ & 35.5077 & 34.5102 & 32.8473 & 40.0194 & $\mathbf{3 1 . 9 4 7 0}$ \\
\hline
\end{tabular}

Table 8. Optimum values for PID-type controller gains, frequency biases and fitness function obtained by GA for Case 2.

\begin{tabular}{rrrrrr}
\hline & \multicolumn{1}{c}{$I S E$} & \multicolumn{1}{c}{ ITAE } & \multicolumn{1}{c}{ ITSE } & \multicolumn{1}{c}{ ISTAE } & \multicolumn{1}{c}{ ISTSE } \\
\hline$K_{P}{ }^{i}$ & 2.1568 & 7.1090 & 7.3798 & 8.3011 & 9.4361 \\
$K_{I}{ }^{i}$ & 8.7097 & 77.2074 & 22.3201 & 137.7736 & 46.2315 \\
$K_{D}{ }^{i}$ & 0.9369 & 1.6112 & 2.2906 & 1.6732 & 2.3504 \\
$B^{i}$ & 5.3036 & 2.4068 & 1.6806 & 2.5333 & 1.4543 \\
$J_{m}$ & 1.3700 & 3801.0699 & 35.4209 & 1027678.5156 & 1953.7130 \\
$J_{c}$ & 58.3010 & 56.2698 & 53.3756 & 74.7886 & $\mathbf{5 1 . 1 5 1 0}$ \\
\hline
\end{tabular}

Table 9. Optimum values for PID-type controller gains, frequency biases and fitness function obtained by GA for Case 3.

\begin{tabular}{rrrrrr}
\hline & \multicolumn{1}{c}{$I S E$} & \multicolumn{1}{c}{ ITAE } & \multicolumn{1}{c}{ ITSE } & \multicolumn{1}{c}{ ISTAE } & \multicolumn{1}{c}{ ISTSE } \\
\hline$K_{P}{ }^{i}$ & 1.5892 & 9.4166 & 9.7988 & 6.1887 & 5.0431 \\
$K_{I}{ }^{i}$ & 8.0690 & 83.5681 & 31.6823 & 101.3438 & 26.1168 \\
$K_{D}{ }^{i}$ & 0.6833 & 2.0075 & 2.9203 & 1.2508 & 1.2350 \\
$B^{i}$ & 7.3000 & 1.6746 & 1.3093 & 3.3909 & 2.7601 \\
$J_{m}$ & 2.0295 & 4351.3798 & 50.4309 & 1142001.3002 & 2767.6081 \\
$J_{c}$ & 74.6823 & 69.3386 & $\mathbf{6 3 . 7 0 7 8}$ & 90.3766 & 64.0060 \\
\hline
\end{tabular}

\section{Conclusions}

The important role of AGC will continue in restructured electricity markets, but with modifications. Bilateral contracts can exist between DisCos in one control area and GenCos in other control areas. The use of a DPM facilitates the simulation of these bilateral contracts. So, the modified AGC scheme in a deregulated environment includes contract data and measurements along with the various possible types of contracts combinations. In this new restructured environment, GenCos sell power to various DisCos at competitive prices, and the minimization of the total cost in this open market, is one of the most important aspects. In this context, the tuning of area controllers in an AGC deregulated system is discussed and applied. It is evident that in this tuning process, GAs are a valuable tool and provide quite easily the best answers for such a kind of problems. Controller gains and frequency biases are obtained for I-type, PI-type and PID-type controllers for a two-area interconnected restructured thermal power system with reheat turbines. Several performance indices are considered. These include in addition to the popular integral square of the error (ISE), the integral of time-multiplied absolute value of the error (ITAE), the integral of time-multiplied square of the error (ITSE), the integral of squared time-multiplied absolute value of the error (ISTAE), and the integral of squared timemultiplied square of the error (ISTSE). For each performance index, digital simulations of the system are carried out and 

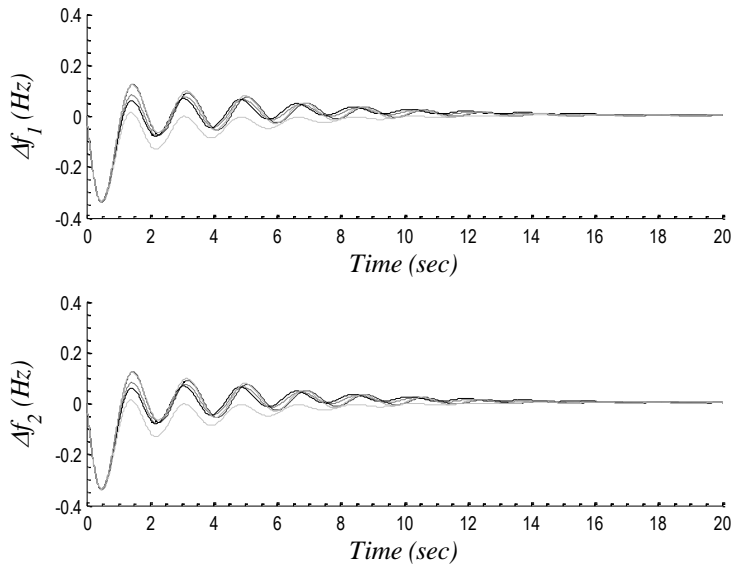

(a)
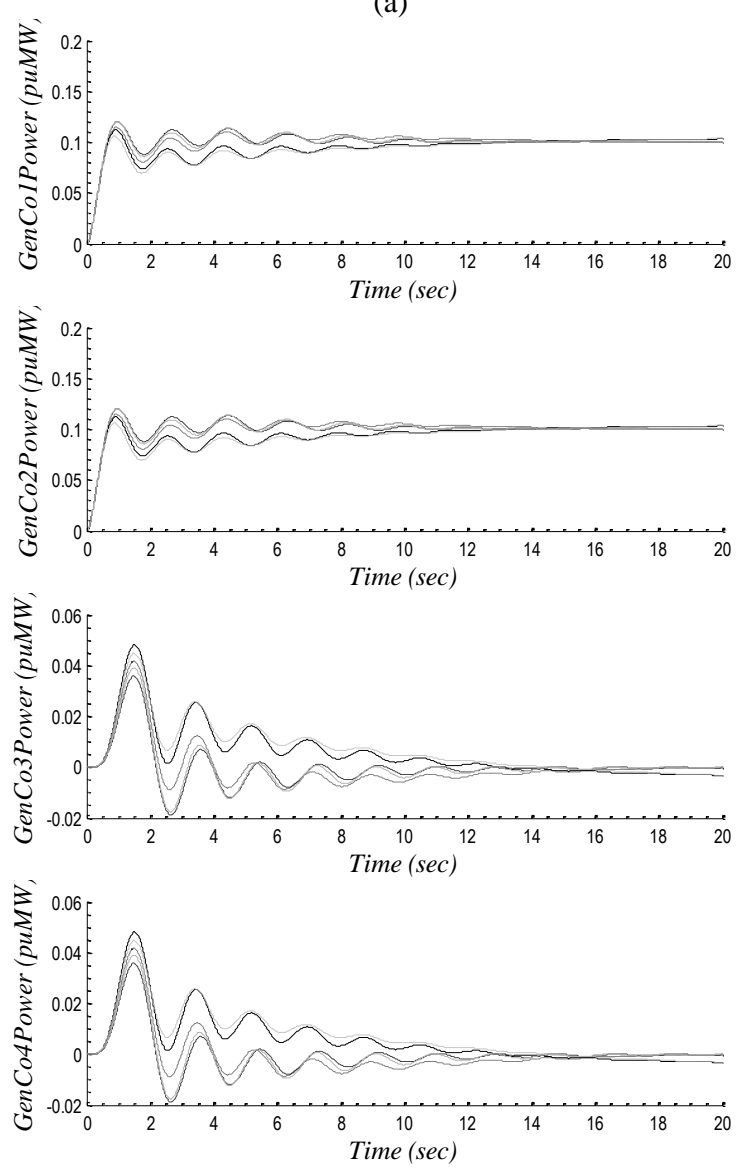

(b)

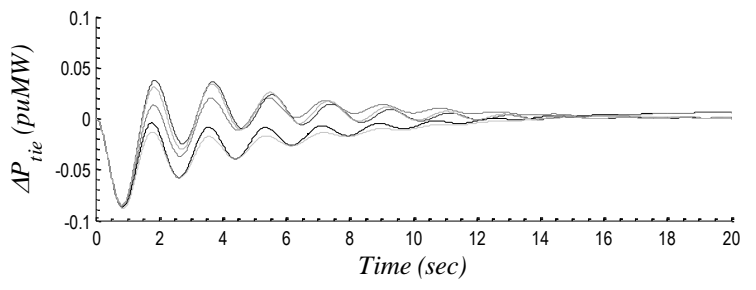

(c)

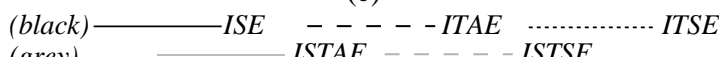

(grey) $\longrightarrow$ ISTAE $-\ldots-\ldots$ ISTSE

Figure 8. Transient system's responses for Case 1 with I-type control w.r.t. the five performance indices: (a) frequency deviations, (b) Tie line power, (c) GenCos' generated power.
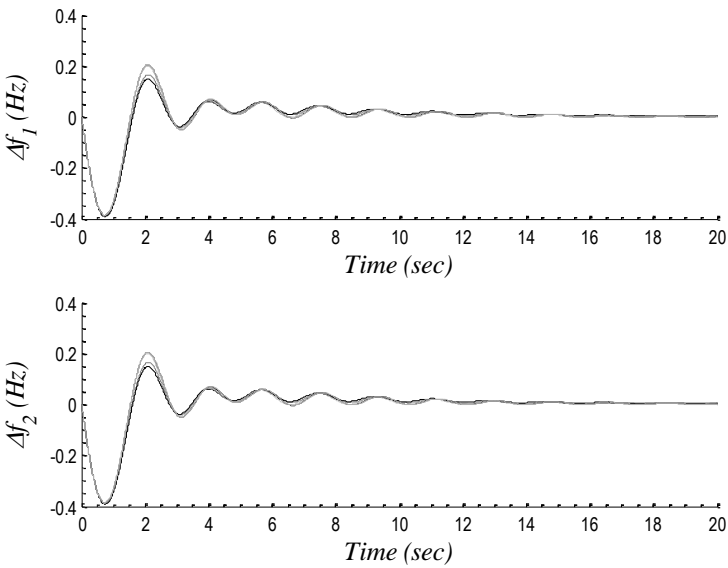

(a)
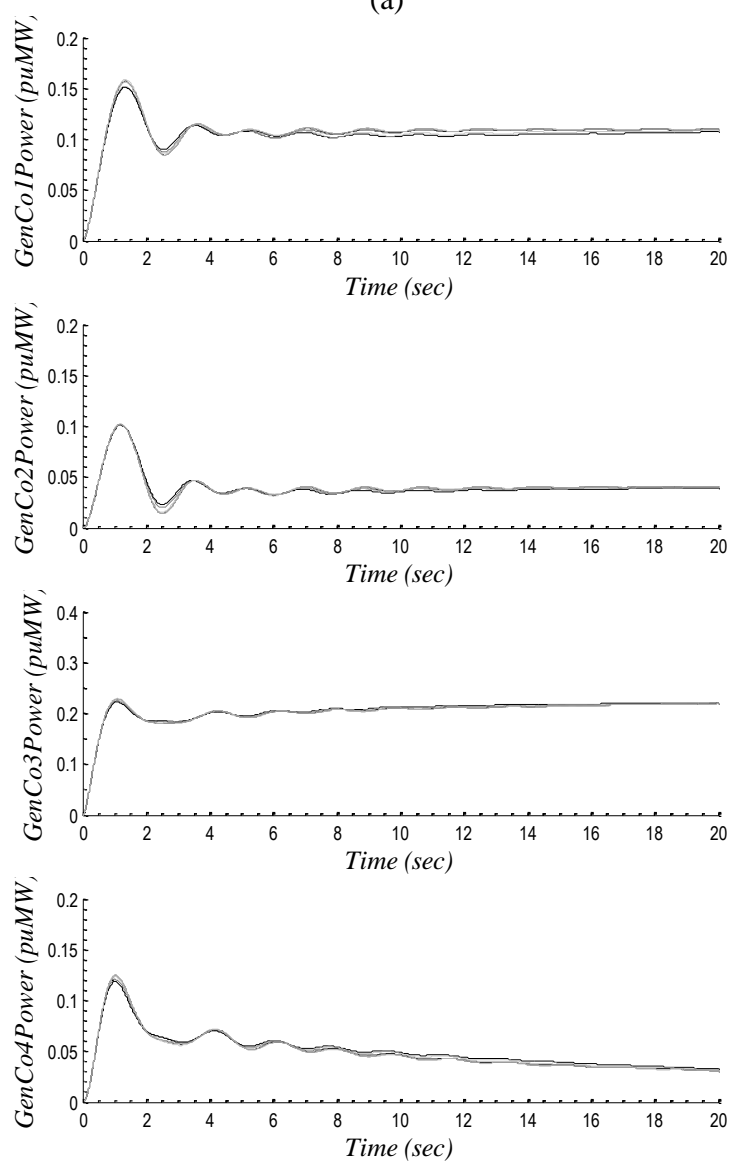

(b)

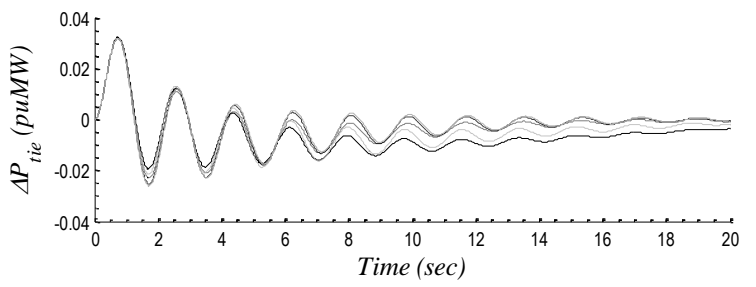

(c)

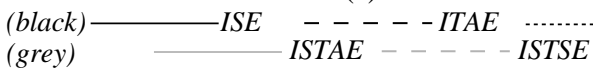

ITSE

Figure 9. Transient system's responses for Case 2 with I-type control w.r.t. the five performance indices: (a) frequency deviations, (b) Tie line power, (c) GenCos' generated power. 

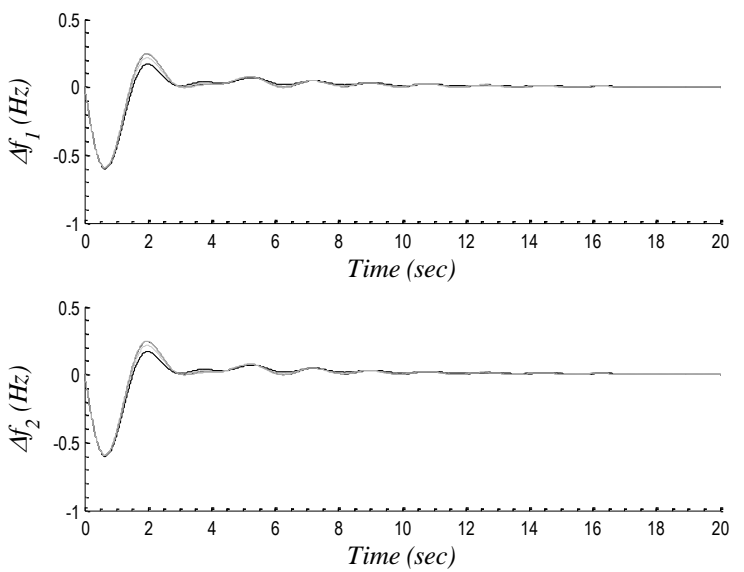

(a)
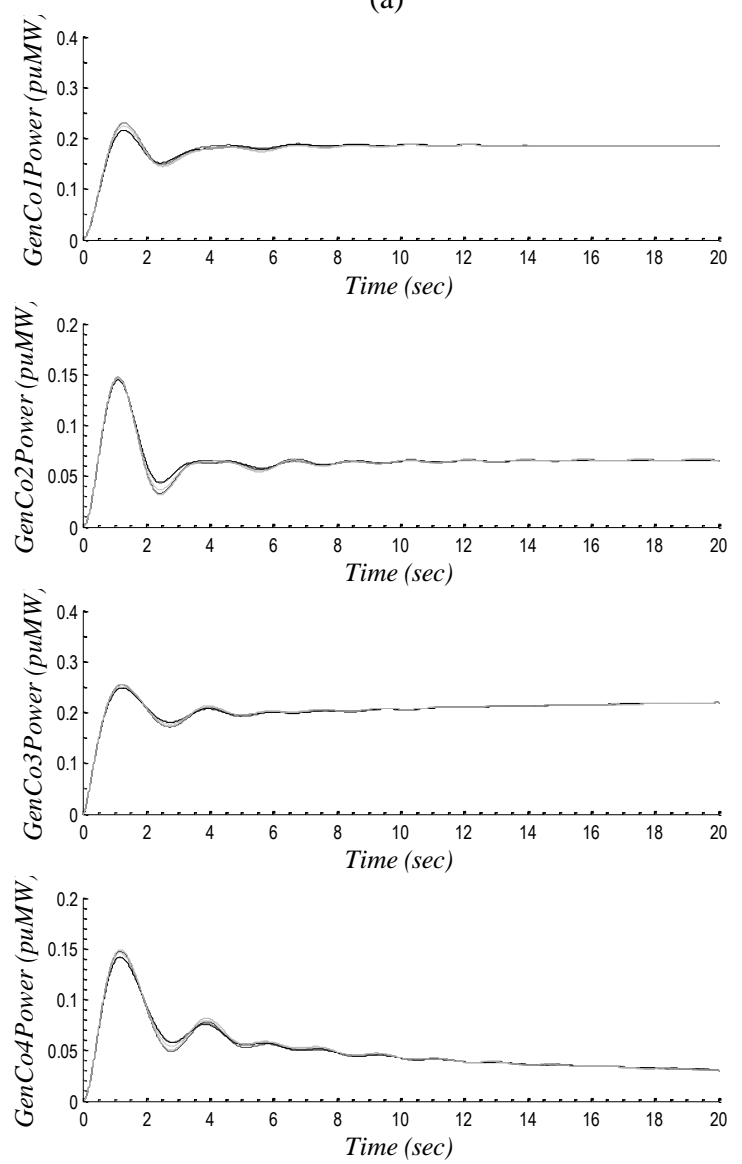

(b)

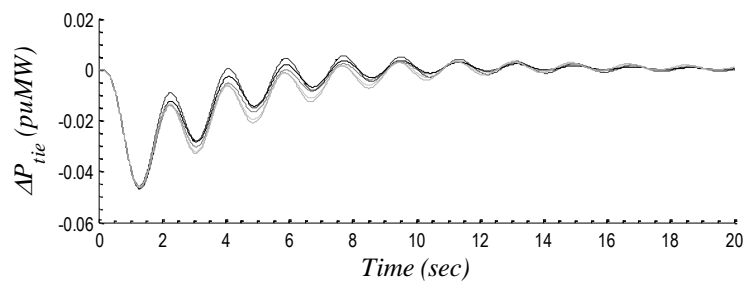

(c)

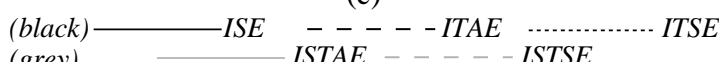

(grey) $\longrightarrow$ ISTAE $-\ldots-\ldots$ ISTSE

Figure 10. Transient system's responses for Case 3 with I-type control w.r.t. the five performance indices: (a) frequency deviations, (b) Tie line power, (c) GenCos' generated power.
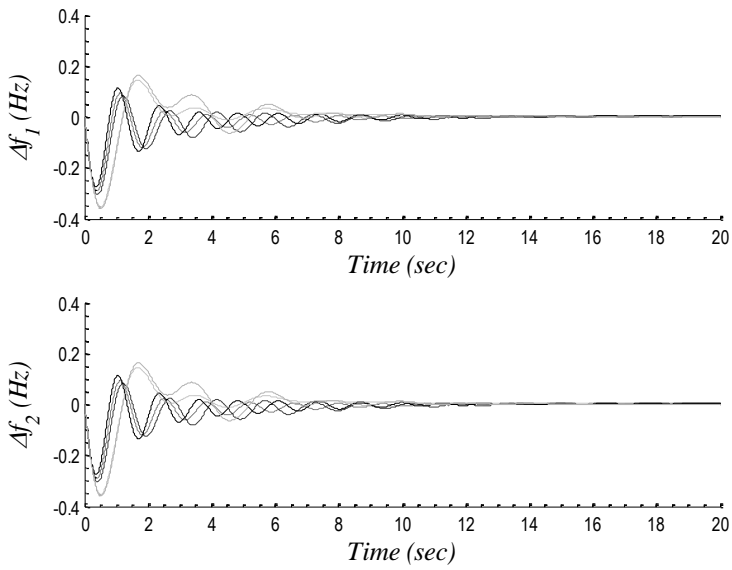

(a)
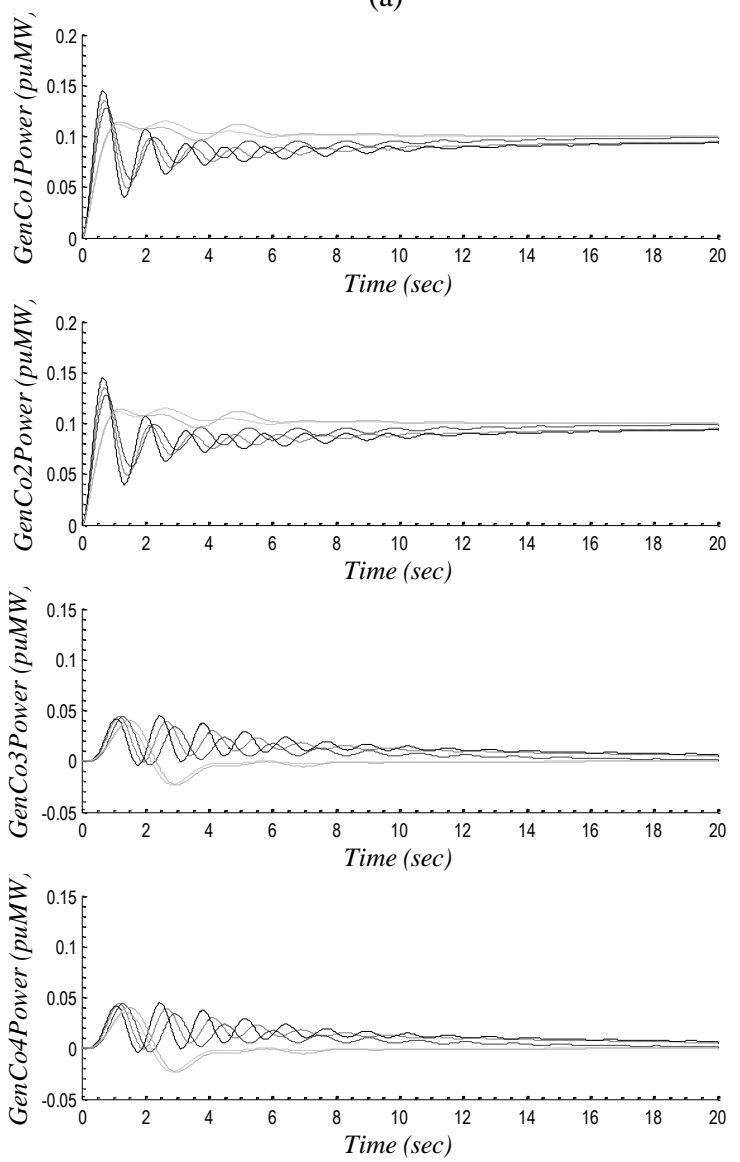

(b)

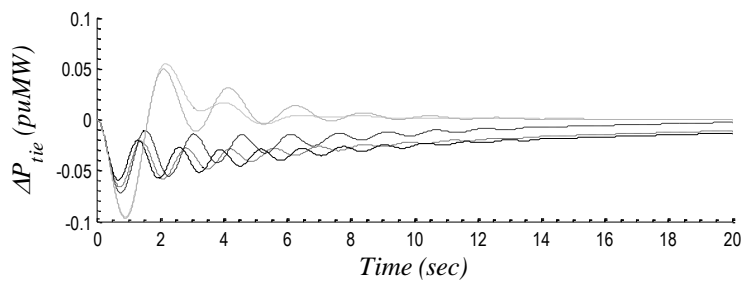

(c)

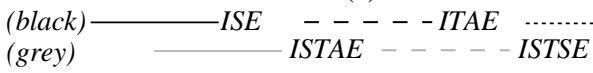

ITSE

Figure 11. Transient system's responses for Case 1 with PI-type control w.r.t. the five performance indices: (a) frequency deviations, (b) Tie line power, (c) GenCos' generated power. 

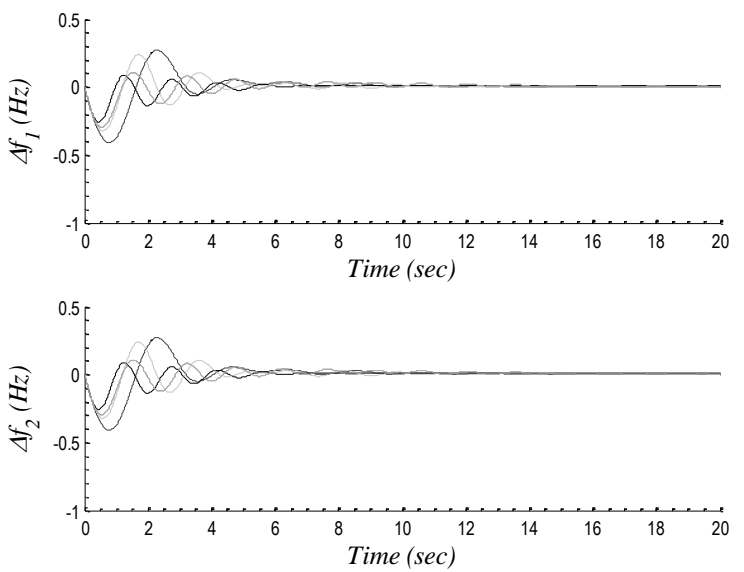

(a)
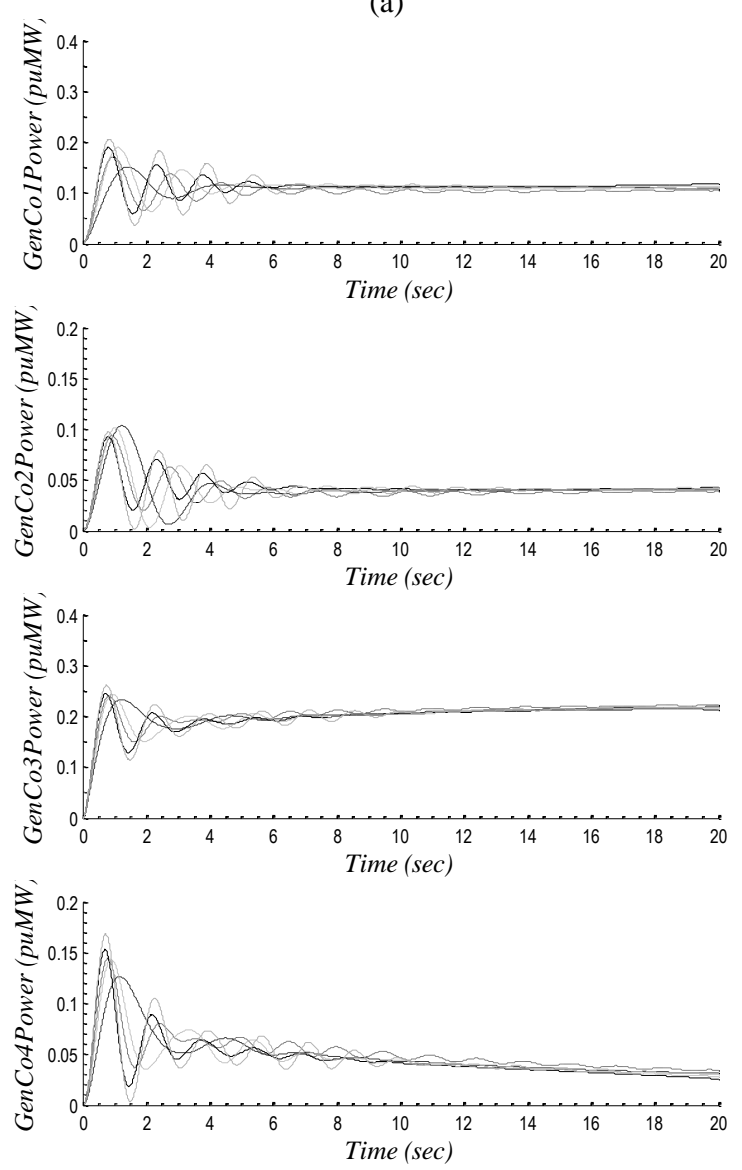

(b)

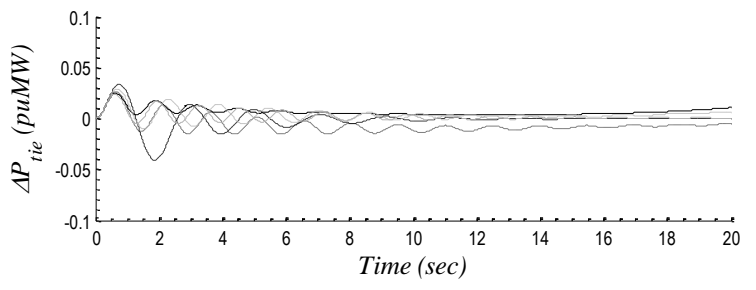

(c)

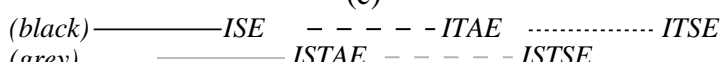

(grey) $\longrightarrow$ ISTAE $-\ldots--$ ISTSE

Figure 12. Transient system's responses for Case 2 with PI-type control w.r.t. the five performance indices: (a) frequency deviations, (b) Tie line power, (c) GenCos' generated power.
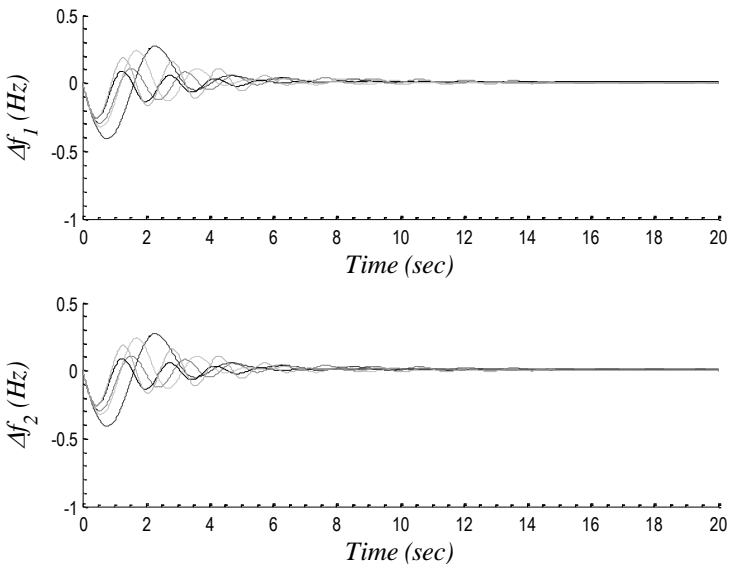

(a)
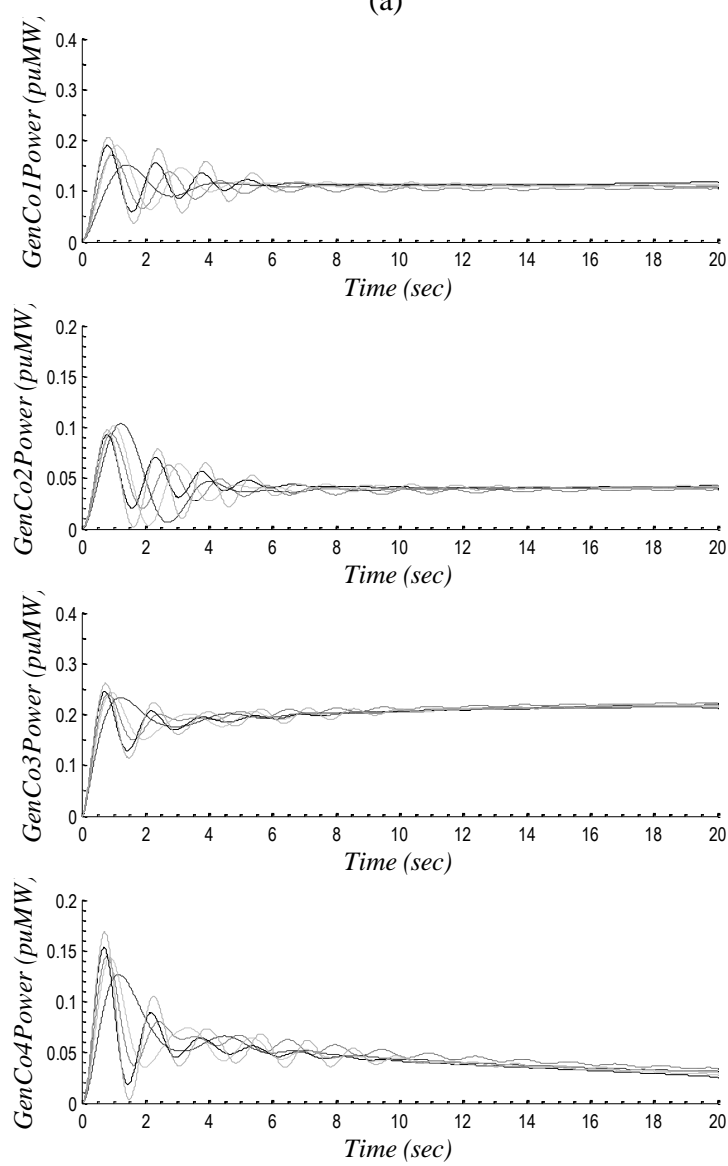

(b)

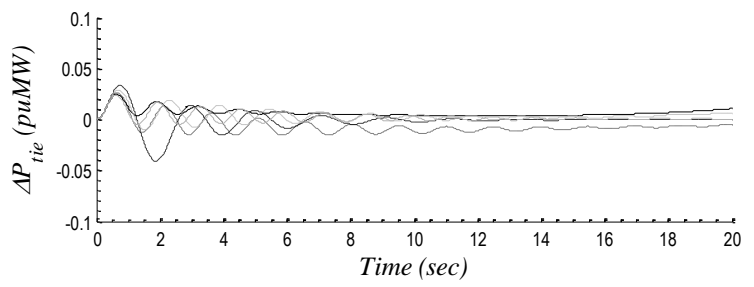

(c)

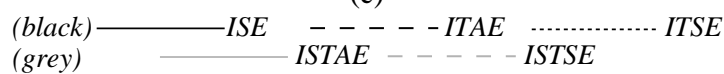

Figure 13. Transient system's responses for Case 3 with PI-type control w.r.t. the five performance indices: (a) frequency deviations, (b) Tie line power, (c) GenCos' generated power. 

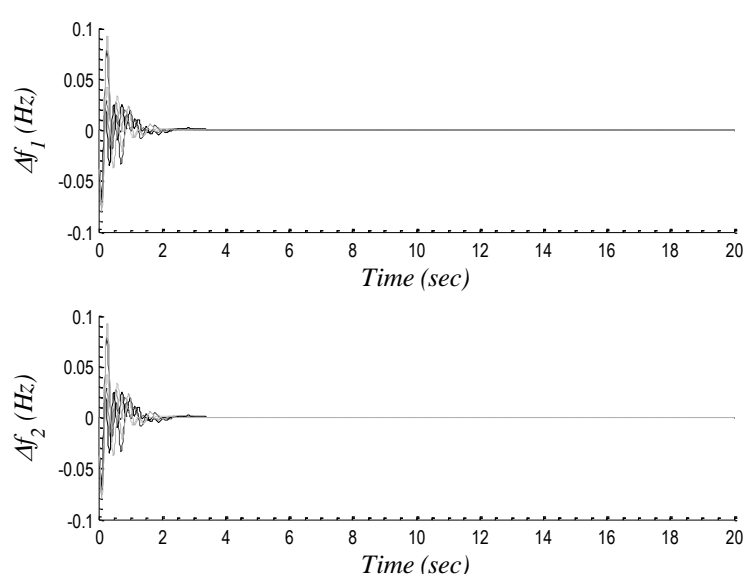

(a)
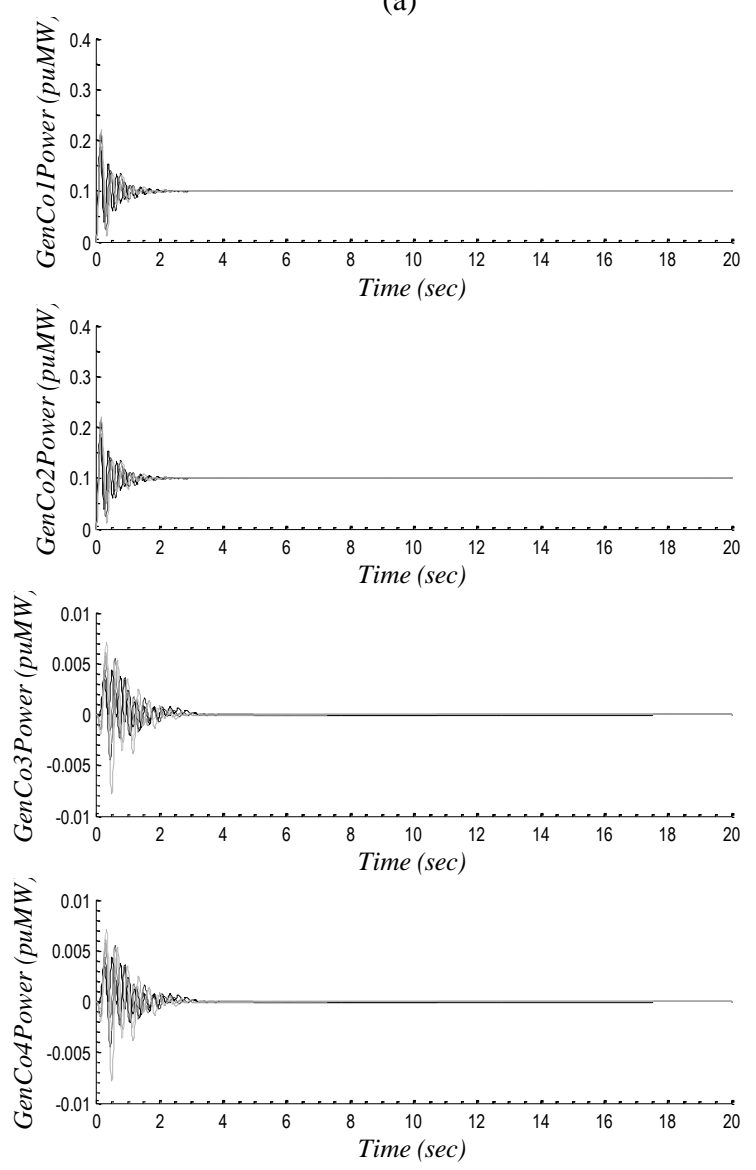

(b)

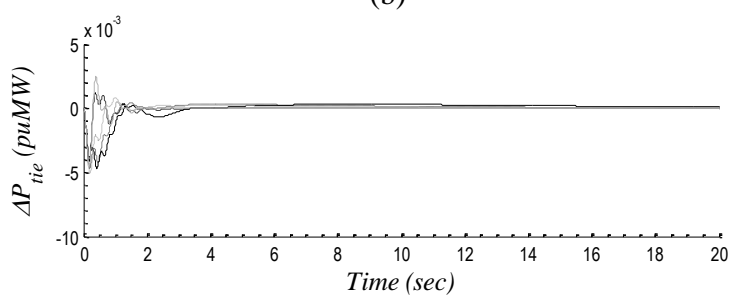

(c)

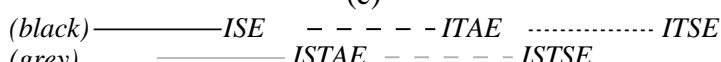

(grey) ISTAE $\longrightarrow \ldots-$ ISTSE

Figure 14. Transient system's responses for Case 1 with PID-type control w.r.t. the five performance indices: (a) frequency deviations, (b) Tie line power, (c) GenCos' generated power.
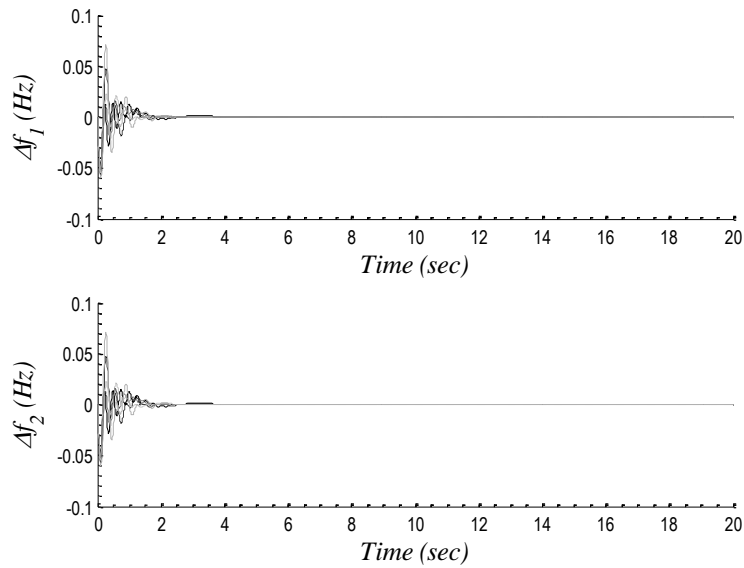

(a)
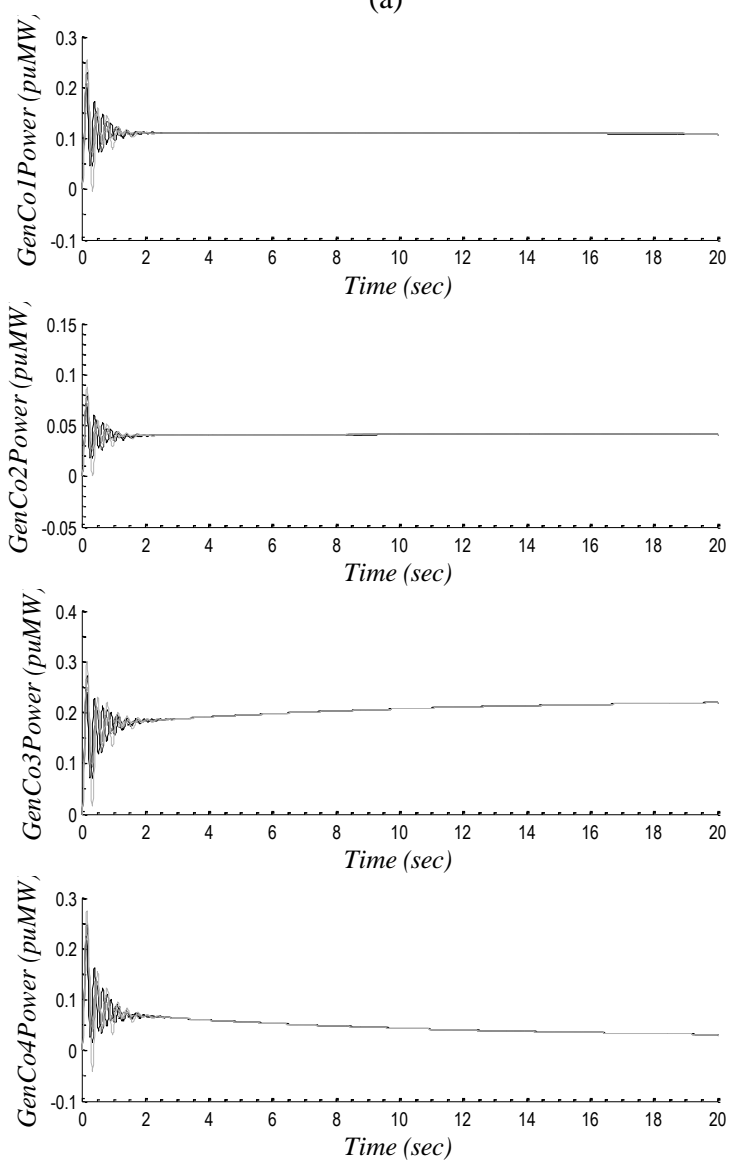

(b)

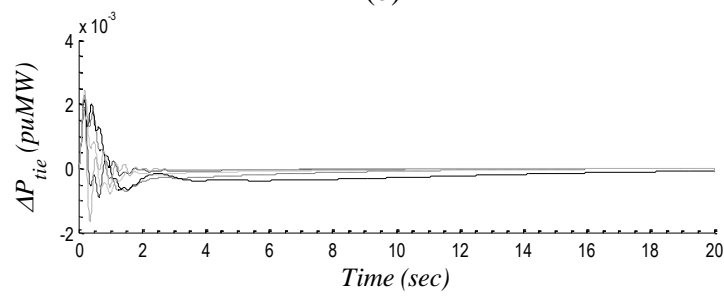

(c)

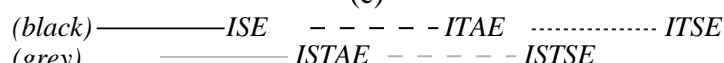

(grey) $\longrightarrow$ ISTAE $-\ldots-\ldots$ ISTSE

Figure 15. Transient system's responses for Case 2 with PID-type control w.r.t. the five performance indices: (a) frequency deviations, (b) Tie line power, (c) GenCos' generated power. 

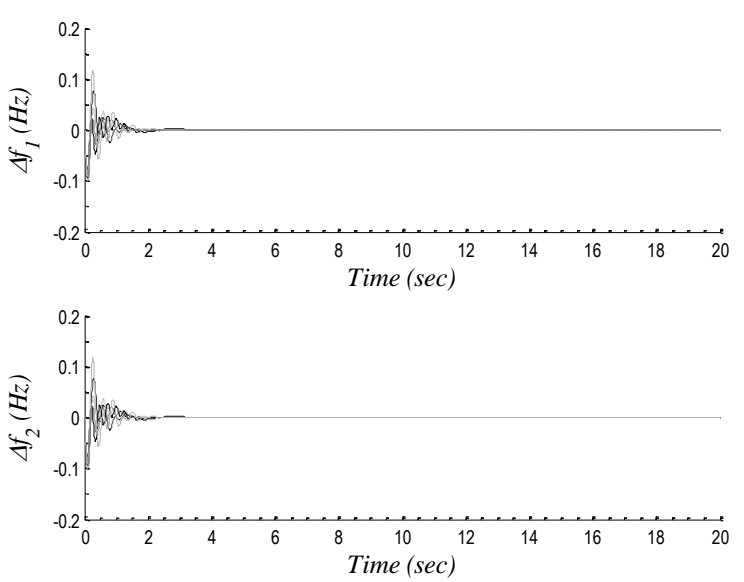

(a)
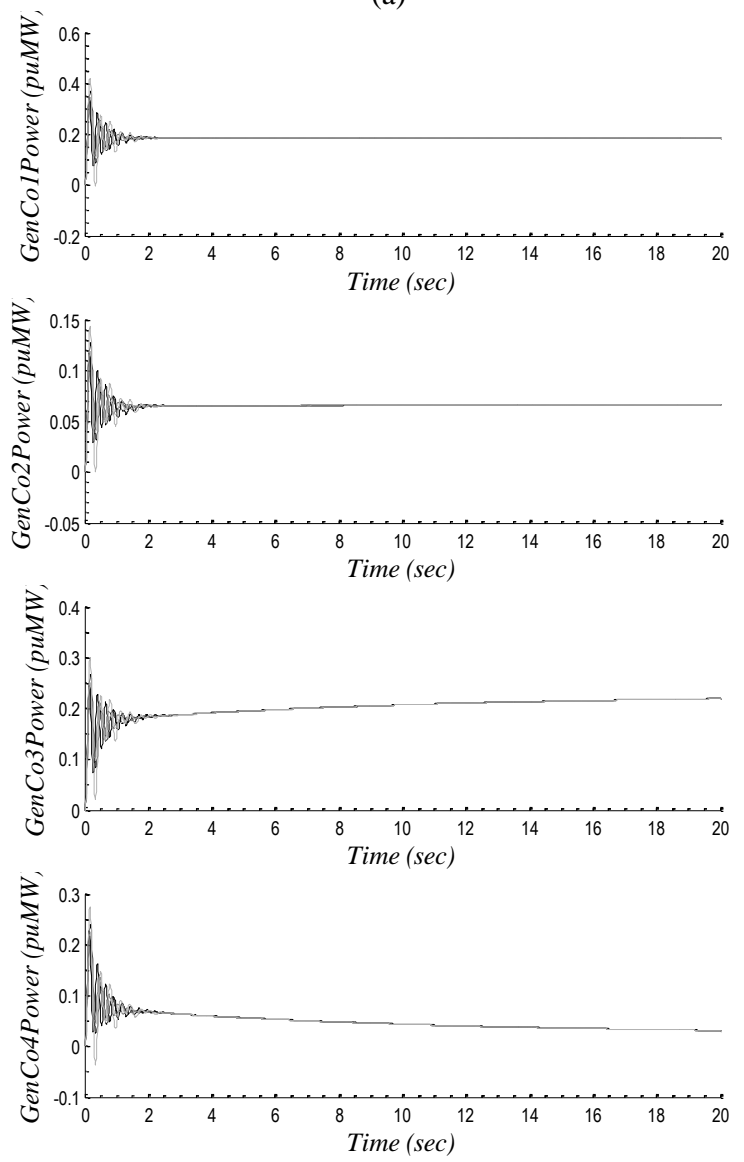

(b)

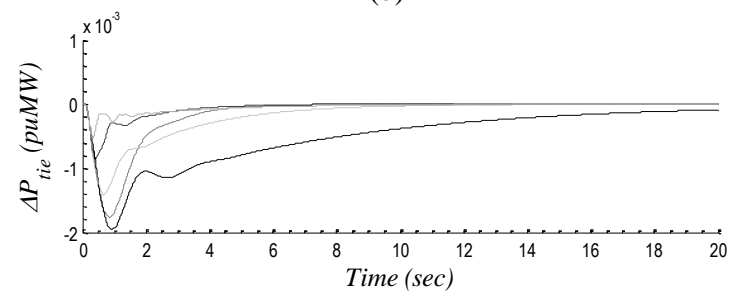

(c)

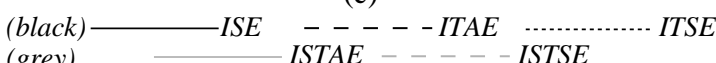

(grey) $\longrightarrow$ ISTAE $-\ldots--$ ISTSE

Figure 16. Transient system's responses for Case 3 with PID-type control w.r.t. the five performance indices: (a) frequency deviations, (b) Tie line power, (c) GenCos' generated power. optimization of the parameters of the AGC systems is achieved in a simple and elegant manner through the effective application of genetic algorithms. It is clear that the dynamic performance of the system, using the optimal parameters, is resulting from the minimization of a different performance index (and not only the ISE usually used in literature). It is also seen that the choice of the objective function is important and affects the behavior of the system. This way, the lack of poor damping and settling time (relative to the other indices) as well as the improvement of the transient error in both the frequency and tie-line power, can be assured. Also, the results obtained indicate the appropriateness of I or PI over the PID strategy. Further work should include multi area systems, new controller structures as well as different power system characteristics i.e. hydro and diesel units for the GenCos.

\section{Nomenclature}

\begin{tabular}{|c|c|}
\hline$f_{i}, \Delta f_{i}$ & power system frequency, deviation of \\
\hline$P_{r i}$ & area's $i$ nominal installed capacity \\
\hline$\Delta P_{L i}$ & area's $i$ load disturbance \\
\hline$\Delta P_{t i e}$ & interchange area's tie line error \\
\hline$P_{t j}$ & $\begin{array}{l}\text { turbine's block output signal of generation } \\
\text { company } j\end{array}$ \\
\hline$P_{g j}$ & $\begin{array}{l}\text { governor's block output signal of } \\
\text { generation company } j\end{array}$ \\
\hline$K_{p s i}, T_{p s i}$ & $\begin{array}{l}\text { power system's block gain and time } \\
\text { constant of area } i\end{array}$ \\
\hline$K_{t j}, T_{t j}$ & $\begin{array}{l}\text { turbine's block gain and time constant of } \\
\text { generation company } j\end{array}$ \\
\hline$K_{g j}, T_{g j}$ & $\begin{array}{l}\text { governor's block gain and time constant of } \\
\text { generation company } j\end{array}$ \\
\hline$K_{r j}, T_{r j}$ & $\begin{array}{l}\text { reheater's block gain and time constant of } \\
\text { generation company } j\end{array}$ \\
\hline$R_{j}$ & $\begin{array}{l}\text { governor droop parameter of generation } \\
\text { company } j\end{array}$ \\
\hline$B_{i}$ & area's $i$ frequency bias parameter \\
\hline$c p f$ & contract participation factor \\
\hline apf & area participation factor \\
\hline$u_{i}$ & area's $i$ controller's output signal \\
\hline$K_{P}, K_{I}, K_{D}$ & $\begin{array}{l}\text { proportional, integral and derivative gains } \\
\text { of a PID structure controller }\end{array}$ \\
\hline$J$ & performance index \\
\hline$F$ & fitness function of the genetic algorithm \\
\hline$T_{s}, \Delta t$ & simulation and sampling time \\
\hline$\alpha, \beta$ & weight values used by the fitness function \\
\hline$P_{c}$ & genetic algorithm's crossover rate \\
\hline$P_{m}$ & genetic algorithm's mutation rate \\
\hline$\lambda$ & chromosome's bit length \\
\hline$x^{u}, x^{l}$ & $\begin{array}{l}\text { genetic algorithm variable upper and lower } \\
\text { bounds }\end{array}$ \\
\hline$z^{-1}$ & discrete time system delay \\
\hline
\end{tabular}




\section{Appendix A: Power System Data}

$P_{r 1}=P_{r 2}=2000 \mathrm{MW}, f_{o}=60 \mathrm{~Hz}$,

$K_{p s}=K_{p s 2}=120 \mathrm{~Hz} / \mathrm{puMW}, T_{p s l}=T_{p s 2}=20 \mathrm{sec}$,

$K_{t 1}=K_{t 2}=K_{t 3}=K_{t 4}=0.5, T_{t 1}=T_{t 2}=T_{t 3}=T_{t 4}=0.3 \mathrm{sec}$,

$K_{g 1}=K_{g 2}=K_{g 3}=K_{g 4}=1, T_{g 1}=T_{g 2}=T_{g 3}=T_{g 4}=0.08 \mathrm{sec}$,

$K_{r 1}=K_{r 2}=K_{r 3}=K_{r 4}=0.5, T_{r 1}=T_{r 2}=T_{r 3}=T_{r 4}=10.0 \mathrm{sec}$,

$R_{1}=R_{2}=R_{3}=R_{4}=2.4 \mathrm{~Hz} / \mathrm{puMW}, T_{12}=0.545 \mathrm{puMW}$,

$a_{121}=a_{122}=-1, B_{0}=0.425 \mathrm{puMW} / \mathrm{Hz}$.

\section{Appendix B: Genetic Algorithm Parameters}

\begin{tabular}{lc}
\hline Parameter & Value \\
\hline Maximum no of generations $*$ & 30 \\
No of population size & 50 \\
Uniform crossover & Yes \\
Crossover probability & 1.0 \\
Elitism & Yes \\
Mutation probability & 0.005 \\
Creep mutations & Yes \\
Creep mutation probability & 0.02 \\
\hline
\end{tabular}

\section{References}

Abdel-Magid Y.L., Dawoud M.M., 1997. Optimal AGC tuning with genetic algorithms, Electric Power Systems Research, Vol. 38, pp. 231-238.

Aditya S.K., Das D., 2003. Design of load frequency controllers using genetic algorithms for two area interconnected hydro power system, Electric Power Components and Systems, Vol. 31, No. 1, pp. 81-94.

Ai-Hamouz Z.M., Abdel-Magid Y.L., 1993. Variable structure load frequency controller for multiarea power systems, Int. Journal of Electric Power and Energy Systems, Vol. 15, No. 5, pp. 90-101.

Bevrani H., Mitani Y., and Tsuji K., 2004. Robust decentralized AGC in a restructured power system. Energy Conversion \& Management, Vol. 45, pp. 2297-2312.

Christie R., Bose A., 1996. Load-frequency control issues in power systems operation after deregulation. IEEE Trans. on Power Systems, Vol. 11, pp. 1191-1200.

Christie R.D., Wollenberg B.F., and Wangensteen I., 2000. Transmission management in the deregulated environment. Proc. IEEE Special Issue on The Technology of Power System Competition, Vol. 88, No. 2, pp. 170-195.

Cohn N., 1986. Control of generation and power flow on interconnected systems. Wiley, New York.

Delfino B., Fornari F., and Massucco S., 2002. Load-frequency control and inadvertent interchange evaluation in restructured power systems. Proc. IEE Gen. Trans. Distr., Vol. 149, No. 5, pp. 607-614.

Demiroren A., Zeynelgil H.L., 2007. GA application to optimization of AGC in three-area power system after deregulation. International Journal of Electrical Power \& Energy Systems, Vol. 29, No. 3, pp. 230-240.

Donde V., Pai M.A., and Hiskens I.A., 2001. Simulation and optimization in an AGC system after deregulation. IEEE Trans. on Power Systems, Vol. 16, No. 3, pp. 481-489.

Elgerd O.I., 1970. Optimum megawatt-frequency control of multi-area electric energy systems. IEEE Trans. on PAS, Vol. 89, No. 4, pp. 556-563.

Fleming P.J., Fonseca C.M., 1993. Genetic algorithms in control systems engineering, Research Report No. 470, Dept. of Automatic Control and Systems Engineering, University of Sheffield, Sheffield, UK.

Grefenstette J.J., 1986. Optimization of control parameters for genetic algorithms. IEEE Trans. on System, Man and Cybernetics, Vol. SMC-16, pp. 122-128.

Holland J.H., 1975. Adaptation in Nature and Artificial Systems. University of Michigan Press.

Ibraheem, Singh O., Hasan N., 2009. Genetic Algorithm Based Scheme for Optimization of AGC Gains of Interconnected Power System. Journal of Theoretical and Applied Information Technology, Vol. 12, No. 1, pp. 33-39.

Ilic M., Galiana F., and Fink L., Eds., 1998. Power Systems Restructuring: Engineering \& Economics. Boston: Kluwer Academic Publishers.

Karnavas Y.L., 2005. On the Optimal Control of Interconnected Electric Power Systems in a Re-Structured Environment Using Genetic Algorithms, WSEAS Transactions on Systems Journal, Vol. 4, No. 8, pp. 1248-1258.

Karnavas Y.L., Papadopoulos D.P., 2002. AGC for autonomous power station using combined intelligent techniques. Int. J. Electric Power Systems Research, Vol. 62, pp. 225-239.

Kumar A., Malik O.P., and Hope G.S., 1985. Variable-structure-system control applied to AGC of an interconnected power system. IEE Proc. Part C, Vol. 132, No. 1, pp. 23-29.

Kumar J., Ng K.H., Sheble G., 1997. AGC simulator for price-based operation-part I: A model. IEEE Trans. on Power Systems, Vol. 12, No. 2, pp. 527-532.

Lin C. Hajela Y.P., 1992. Genetic algorithms in optimization problems with discrete and integer design variables. Engineering Optimization, Vol. 19, No. 4, pp. 309-327. 
Nobile E., Bose A., and Tomsovic K., 2000. Bilateral market for load following ancillary services. Proc. PES Summer Power Meeting, July 15-21, Seattle, WA.

Pan C.T., Lian C.M., 2005. An adaptive controller for power system load frequency control. IEEE Transactions on Power Systems, Vol. 4, No. 1, pp. 122-128.

Shayeghi H., Shayanfar H.A., Jalili A. 2006. Multi stage fuzzy PID power system automatic generation controller in the deregulated environment. Energy Conversion and Management, Vol. 47, No. 18, pp. 2829-2845.

Sheble G.B., 1999. Computational Auction Mechanisms for Restructured Power Industry Operation. Boston: Kluwer Academic Publishers.

Sinha S.K., Prasad R., Patel R.N., 2010. Automatic generation control of restructured power systems with combined intelligent techniques. International Journal of Bio-Inspired Computation, Vol. 2, No.2, pp. 124-131.

Srinivasa R.C., Siva N.S, Sangameswara R.P., 2008. AGC Tuning of TCPS Based Hydrothermal System under Open Market Scenario with Particle Swarm Optimization, J. Electrical Systems, Vol. 4, No. 2, pp. 1-13.

Wu C. J., Huang C.H., 1997. A Hybrid Method for Parameter Tuning of PID Controllers. Journal of Franklin Institute, JFI-334B, pp. 547-562.

\section{Biographical notes:}

Dr. Eng. Yannis L. Karnavas is Assistant Professor at the Department of Electrical Engineering, Technological Educational Institution of Crete, Heraklion, Crete, Hellas. He has engaged in teaching and research activities the last 15 years. His fields of expertise are the analysis and modeling of power systems and electric machines, the design and application of various types of controllers and artificial intelligence methods application to them. Dr.Eng. Karnavas has published several papers in various national, international journals and conferences as well as book chapters in international engineering books. He has also participated in research projects as research leader or scientific associate.

Konstantinos S. Dedousis is a graduate Electrical Engineer from the Department of Electrical Engineering, Technological Educational Institution of Crete, Heraklion, Crete, Hellas. He has done extensive work on the field of modeling of power systems with various types of generating sources and also the field of designing load frequency controllers for them. Presently, he is focusing on analysis of permanent magnet synchronous generators and their implementation in power system studies.

Received November 2009

Accepted March 2010

Final acceptance in revised form March 2010 